\title{
EL MUNDO FUNERARIO DEL EXTREMO SUROCCIDENTAL DE HiSPANIA A TRAVÉS DE DOS CIUDADES: OSSONOBA VERSUS ONOBA*
}

\begin{abstract}
RESUMEN
En este artículo se presenta una breve panorámica de los restos constatados en las necrópolis de dos ciudades portuarias vecinas como son Ossonoba y Onoba, con especial incidencia en las septentrionales por ser las mejor conocidas. Con este trabajo se pretende demostrar que a pesar de la división administrativa existente entre ambas, sus costumbres funerarias resultaron singulares al compartir un horizonte cultural previo.

Recibido: 19/02/2014

Aceptado: $16 / 03 / 2014$

Publicado: 20/05/2014
\end{abstract}

\section{Palabras Clave}

Horizonte cultural; Necrópolis; Sepulturas romanas; Ritual; Ajuar.

\author{
João Pedro Bernardes \\ Universidade do Algarve \\ Lucía Fernández SuTILO \\ Juan Manuel Campos Carrasco \\ Universidad de Huelva \\ Carlos Pereira
}

Universidade de Lisboa

\section{ABSTRAC}

This work provides a brief overview of the archaeological remains found in the Roman necropolis of two important neighbouring harbour towns, such as Ossonoba and Onoba, especially the northerly ones because this are the most know. We intend demonstrate that, notwithstanding the Roman administrative division between them, the funerary practices are particularly similar because they shared an also similar previous cultural horizon.

\section{KEYWORDS}

Cultural horizon; Necropolis; Roman graves; Funerary rituals; Grave goods.

\footnotetext{
* Este artículo se inscribe dentro del Proyecto de Investigación "Funus Onobense: el mundo funerario romano en el occidente de la Baetica" (Ministerio de Ciencia e Innovación. Referencia HAR 204; 23247), perteneciente al Plan Nacional de I+D+i en el marco del Plan Nacional de I+D+i (2008-2011), bajo la dirección del Prof. Dr. Juan M. Campos Carrasco. Igualmente se enmarca dentro del Subproyecto de Investigación I2TEP "MORSUDES", liderado por la Universidad de Huelva, recibe apoyo de la Unión Europea y cofinanciación del Programa Operativo de Cooperación Transfronteriza EspañaPortugal a través del Fondo Europeo de Desarrollo Regional bajo la dirección de los Profs. Drs. Juan M. Campos Carrasco y João Pedro Bernardes.
}

lfsutilo@gmail.com 


\section{INTRODUCCIÓN}

Una vez puesto en marcha el aparato político de Roma, las ciudades de Onoba y Ossonoba quedaron enmarcadas dentro de provincias diferentes, la primera en la Baetica bajo el liderazgo de Cordu$b a$, y la segunda en la Lusitania con Emerita Augusta a la cabeza. A pesar de esta división territorial, las semejanzas entre ambas ciudades resultan innumerables. Desde el punto de vista económico, la existencia de importantes puertos en sendas ciudades, harían del comercio, fundamentalmente de metales, la principal fuente de riquezas y motor de desarrollo. A nivel social, ambas civitas contarían con una población cosmopolita, fuertemente influenciada por la llegada de comerciantes procedentes de otras partes del Imperio, especialmente del Norte de África. Y como no, a nivel funerario, donde la presencia de un mismo horizonte cultural plenamente desarrollado a la llegada de los primeros colonos, supondría el nacimiento de expresiones rituales muy particulares ante la muerte, rastreables en el conjunto de necrópolis de ambas ciudades.
En definitiva, el planteamiento de este artículo persigue caracterizar el panorama funerario del extremo suroccidental de Hispania, sobrepasando los límites territoriales, para enfatizar la adaptación de ese horizonte púnico turdetano a los patrones romanos.

\section{LAS NECRÓPOLIS DE OSSONOBA}

Los hallazgos de sepulturas romanas, referenciados desde el siglo XIX en el área urbana de la ciudad de Faro, posibilitan actualmente tener una localización concreta de las necrópolis romanas de Ossonoba y, consecuentemente, de la extensión y límites de la ciudad romana.

La etimología, que delata orígenes pertenecientes al mismo grupo lingüístico ibérico de Onoba, es ampliamente referida en las fuentes clásicas (Estrabón, III, 2, 5; Pomponio Mela, III, 1; Plinio, IV, 116) y también en la epigrafía y la numismática (IRPC, $3,4,7,8,10)$. A juzgar por los restos conocidos en la época republicana, la ciudad estaba limitada al cerro correspondiente al interior de las murallas. Sólo en el inicio de la época imperial esta ciudad

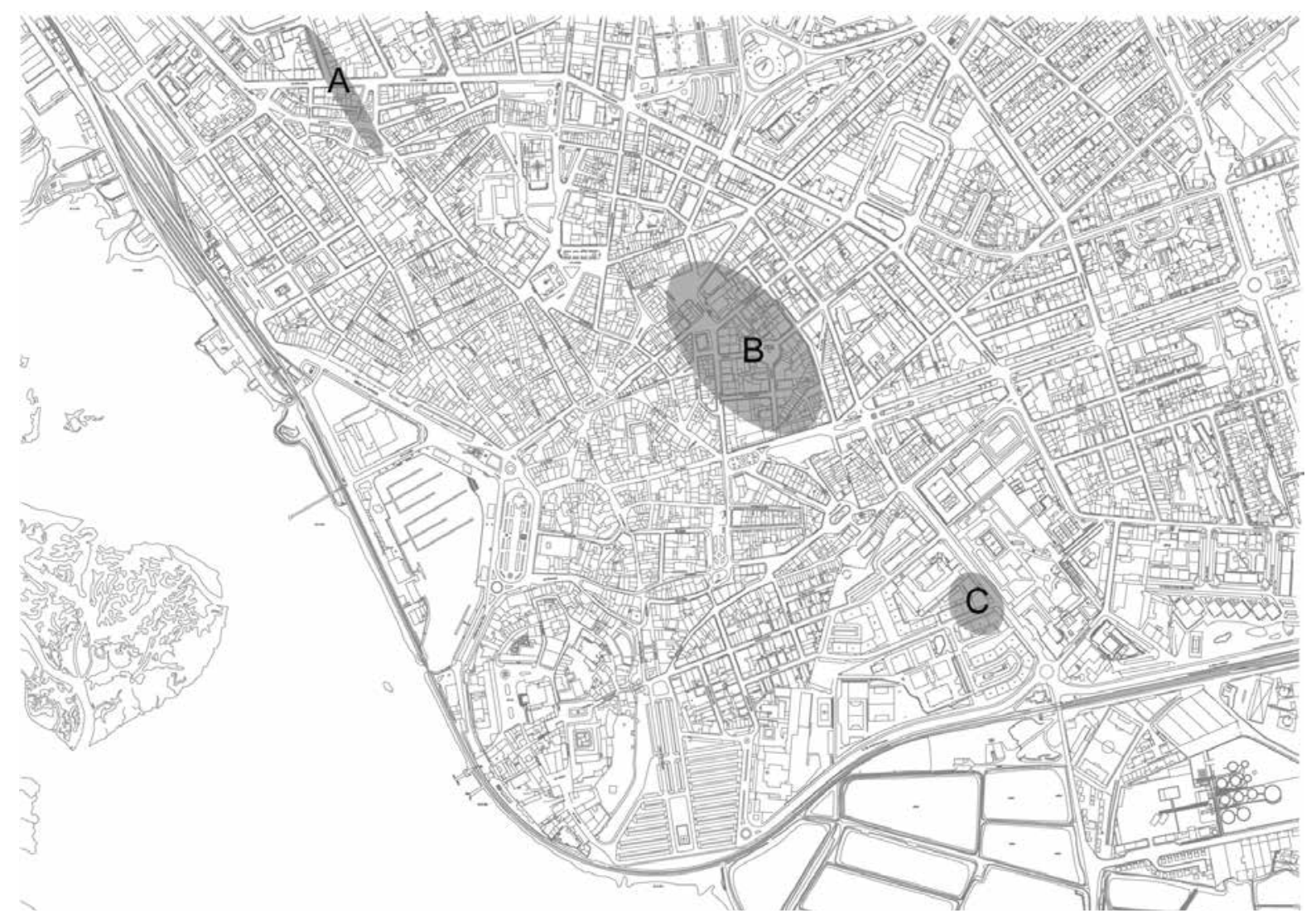

Figura 1. Áreas de la ciudad de Faro donde han sido encontradas sepulturas romanas correspondientes a las necrópolis norte y occidental de Ossonoba y, eventualemente, una necrópolis privada. 
expandirá sus límites alcanzando, en el siglo I, su máxima extensión. Tenía una configuración prolongada determinada por el hecho de haberse expandido a lo largo del margen de la ría y de la vía que seguía para Occidente.

Aunque sean muchas las referencias a hallazgos de tumbas en el área urbana de la ciudad (Rosa, 1984; Viegas, 2011a, 79-98), casi siempre son vagas e imprecisas y, seguramente, no todos los enterramientos de que tenemos noticias datan de época romana. Había, por lo menos, dos necrópolis públicas: la necrópolis Norte, la más grande y mejor conocida, localizada en la zona del antiguo barrio Lethes y que se extendía desde la plazuela das Mouras Velhas hasta Alcaçarias/Pontinha, la cual, una vez traspasados los cursos de agua que limitaban la expansión de la ciudad, se aglomeraba al lado de la vía que salía hacia el Norte y Oriente (Rodrigues, 2004, 45); y en segundo lugar, la necrópolis de la Horta dos Fumeiros/Escola Afonso III que se situaba a lo largo de la vía que salía desde Occidente y de la cual poco se conoce (Rosa, 1984, 151-152). Ésta ocupaba un área que iba desde la plazuela de S. Sebastião, donde en los años sesenta aparecieron tumbas (algunas relacionadas con la iglesia ahí existente), hasta cerca del pabellón deportivo del colegio Afonso III, localizado en la antigua Horta dos Fumeiros. De las muchas sepulturas halladas construidas con tegulae, solo una ha sido recogida por el Museo Municipal (s.a., 1967: 119; Rosa, 1984, 151-152). A mediados de los 80 , cerca de dicha iglesia de S. Sebastião y justo delante de la entrada del actual edificio de la policía, las obras de saneamiento permitieron el hallazgo de algunas sepulturas de tegulae atestiguadas por Teresa Júdice Gamito $(1997,357)$ y José Cabecinha. Insistimos que esta necrópolis romana recorría la vía que salía de la ciudad hacia Occidente, recorriendo la carretera de la Senhora da Saúde (fig. 1).

Una tercera necrópolis está situada en la Horta do Ferragial, entre los edificios de la policía y del Instituto de la Juventud, donde se han conocido varias sepulturas construidas con tegulae (Rosa, 1984, 153). Por su localización, dimensión y características, puede corresponder a un espacio funerario privado de una villa. Muchas necrópolis constatadas en los alrededores de las ciudades son fácilmente asociadas a áreas cementeriales públicas, cuando en realidad puede tratarse de espacios privados. En efecto, en época romana, incluso hasta comienzos de la época Contemporánea, toda esta área, también conocida como Campo da Trindade, constituía una morfología de península en virtud de las ramificaciones de la ría que invadía parte de la actual plazuela de S. Francisco, al Occidente, y parte de los actuales terrenos a Oriente. La localización de la necrópolis en un espacio que no coincide con el trazado de ninguna vía o salida de la ciudad, incluso un poco apartada de ella, unido al exiguo número de tumbas ahí conocidas, pese a que en los últimos años ha sido largamente urbanizada, se ajusta más a la identificación de este espacio con una pequeña necrópolis particular. No obstante, no se debe excluir la posibilidad de que se trate, en efecto, de una tercera necrópolis urbana pública, situada en la zona Sudeste de la ciudad que, al igual que otros núcleos urbanos de la época, estaría circundada por espacios funerarios. Desafortunadamente, la información disponible es escasa, a pesar de que en 1878 , Estácio da Veiga excavó algunas sepulturas en el antiguo Campo da Trindade. De ellas sólo se conocen dos botellas de vidrio y una lucerna depositadas en el Museo Nacional de Arqueología (Alarcão, 1970, 30.v; Cruz, 2009, 47 y 78). En 1973 emergen nuevas noticias de otros enterramientos romanos en el lugar, de los que sólo se recuperaron un plato de terra sigillata africana depositado en el museo de Faro (Rosa, 1984, 153; Bernardes, 2005, 27). Dicho plato, al igual que los materiales recogidos por Estácio da Veiga, tienen una cronología que situamos entre los siglos III-IV d. C.

De las tumbas citadas y localizadas por Pinheiro Rosa en el casco histórico de la ciudad, en la calle Carrasquinho, “...no lugar onde se ergue a casa do falecido conde da Santa Maria” (Rosa, 1984, 151), no se sabe si son romanas. Su emplazamiento, en el interior de la ciudad romana, recuerda a algunos casos como el de Córdoba (Sánchez Ramos, 2007; 2010), donde la retracción de las ciudades en la Antigüedad Tardía supuso que las zonas habitadas durante momentos imperiales fuesen amortizadas por espacios funerarios. Sin embargo, como no se conocen las características de estas tumbas, no podemos afirmar con seguridad si son de dicho momento histórico o posteriores.

También por falta de datos no es posible datar los enterramientos hallados en 1969 entre múltiples estructuras de construcción, cuando se pavimentó la actual área peatonal de la calle de Santo Antonio, referidas por Pinheiro Rosa (1976; 1984, 151) y confirmadas por José Cabecinha. La proximidad tanto de estas tumbas de tegulae "na zona para lá 
da Pontinha" (Rosa, 1976, 40), como de las halladas en esta misma vía en el no 131 (s.a., 1969, 292), a las excavadas en la calle de Alcaçarias, hacen pensar en la existencia de un mismo espacio funerario. Al no existir ningún registro o dato, además de la noticia de su hallazgo, no es posible saber si los enterramientos fueron amortizados por las estructuras o, al contrario, son posteriores a éstas. El primer caso - tumbas amortizadas por estructuras antiguas supone una situación recurrente en las necrópolis republicanas de otras muchas ciudades, donde los espacios funerarios del suburbio terminan siendo conquistados por la expansión urbana, como es el caso de Corduba o Onoba (Vaquerizo y Murillo, 2010, 479; Ruiz Osuna, 2010, 58; Fernández et alii, $2013,179)$, situación inversa a la que es constatada en la Antigüedad Tardía, en cuyo caso serían los enterramientos los que estarían amortizando estructuras urbanas. Aunque los enterramientos de la necrópolis Norte se prolongan hasta el siglo V, no es rara la coexistencia de otros espacios fúnebres, a partir de este momento, en otros puntos de la ciudad.

De todas formas, queda, efectivamente, por aclarar la localización de la necrópolis republicana de la ciudad de Ossonoba, a pesar de que la calle de Santo António sea una de las posibilidades. Todas las restantes referencias al hallazgo de tumbas romanas, principalmente las constatadas en la última década, se emplazan entre la plazuela das Mouras Velhas y Pontinha, asociadas a la necrópolis Norte, el principal espacio funerario de la ciudad que fue ocupado entre el siglo I y el V.

\section{LA NECRÓPOLIS NORTE DE OSSONOBA}

Pertenecían a esta necrópolis, también conocida en la bibliografía como necrópolis del barrio del Colégio o del barrio Lethes, las treinta y ocho tumbas excavadas, en 1878, por Estácio da Veiga delante del teatro Lethes/plazuela das Mouras Velhas (Santos, 1971, 188-192), pero también las siete que Abel Viana registró, en 1938, en la calle D. João de Castro (Viana, 1951), las identificadas en la calle de Santo António (Rosa, 1976, 40; 1984, 151), que fueron intervenidas en una excavación de salvamento, en 1984, por Teresa Gamito en la calle de Alcaçarias (Gamito, 1992) y, más recientemente, las tres que fueron halladas durante los seguimientos, efectuados en 2004, en la calle Dr. João Lúcio/calle de Alcaçarias, en zona anexa a la intervención de 1984, a las que se suman las noventa y una escavadas en la plazuela 25 de Abril (Teichner et alii, 2007, 164), la cinco tumbas "constituídas por tegulae invertidas a servir de tampa e muretes em lateres" en el $\mathrm{n}^{\mathrm{o}} 33 / 35$ de la calle de Portugal (Serra et alli, 2006, 212) y, por fin, las tres tumbas de tegulae identificadas en 2007 en la plazuela das Mouras Velhas, a la que sumamos otra intervenida por los arqueólogos del museo de Faro en la plazuela 25 de Abril, hallada durante un seguimiento de obra (fig. 2). La totalidad de estas intervenciones han permitido identificar cerca de centenar y medio de tumbas, a las que podríamos sumar aún las catorce referidas por Abel Viana descubiertas en el último tramo de la calle João de Deus antes de hallar la de Horta Machado (Viana, 1951, 148), y muchas otras que seguramente fueron destruidas sin registro previo cuando toda la zona fue urbanizada en los años treinta del siglo pasado. Según Abel Viana, en esa época era frecuente el descubrimiento de tumbas, aun cuando no todas ellas eran romanas, realidad que puede ser aplicable a la inhumación hallada en el $\mathrm{n}^{\mathrm{O}} 21$ de la calle João Lúcio, cuyo esqueleto presentaba aún el grillete de hierro en una de las tibias (idem, 146-147). En efecto, este espacio seguiría siendo utilizado como cementerio para enterramientos de épocas posteriores a la romana, especialmente durante la ocupación del local por los Jesuitas.

Toda la vasta área referenciada, se extiende a lo largo de cerca de cinco hectáreas desde la actual plazuela das Mouras Velhas al de Pontinha y los alrededores de la rotonda del tribunal a la calle Horta Machado (antiguo recinto del colegio de los Jesuitas del siglo XVII). Esta era la principal necrópolis urbana de la ciudad, cuya ocupación alargada en el tiempo justifica su elevada extensión, pero también la sucesión vertical de enterramientos bien atestiguados en la excavación de la plazuela 25 de Abril, donde, en $400 \mathrm{~m}^{2}$, fueron identificadas 82 inhumaciones y 9 incineraciones (Teichner et alii, $2007,166)$. Un caso paradigmático que refleja esta situación es la tumba $\mathrm{n}^{\circ} 18$, consistente en una inhumación en ánfora destruida de forma parcial por la tumba $\mathrm{n}^{\mathrm{O}} 61$, consistente en una inhumación en fosa con cubierta de tegulae (fig. 3).

En esta necrópolis de Ossonoba, a semejanza de lo que sucede por todo el imperio romano, y especialmente en Hispania (Vaquerizo, 2010, 282-288), se constata la coexistencia del rito de incineración (crematio) y de inhumación (inumatio). Ya Estácio da Veiga refirió, entre las cuatro decenas de tumbas que excavó en la plazuela das Mouras Vel- 


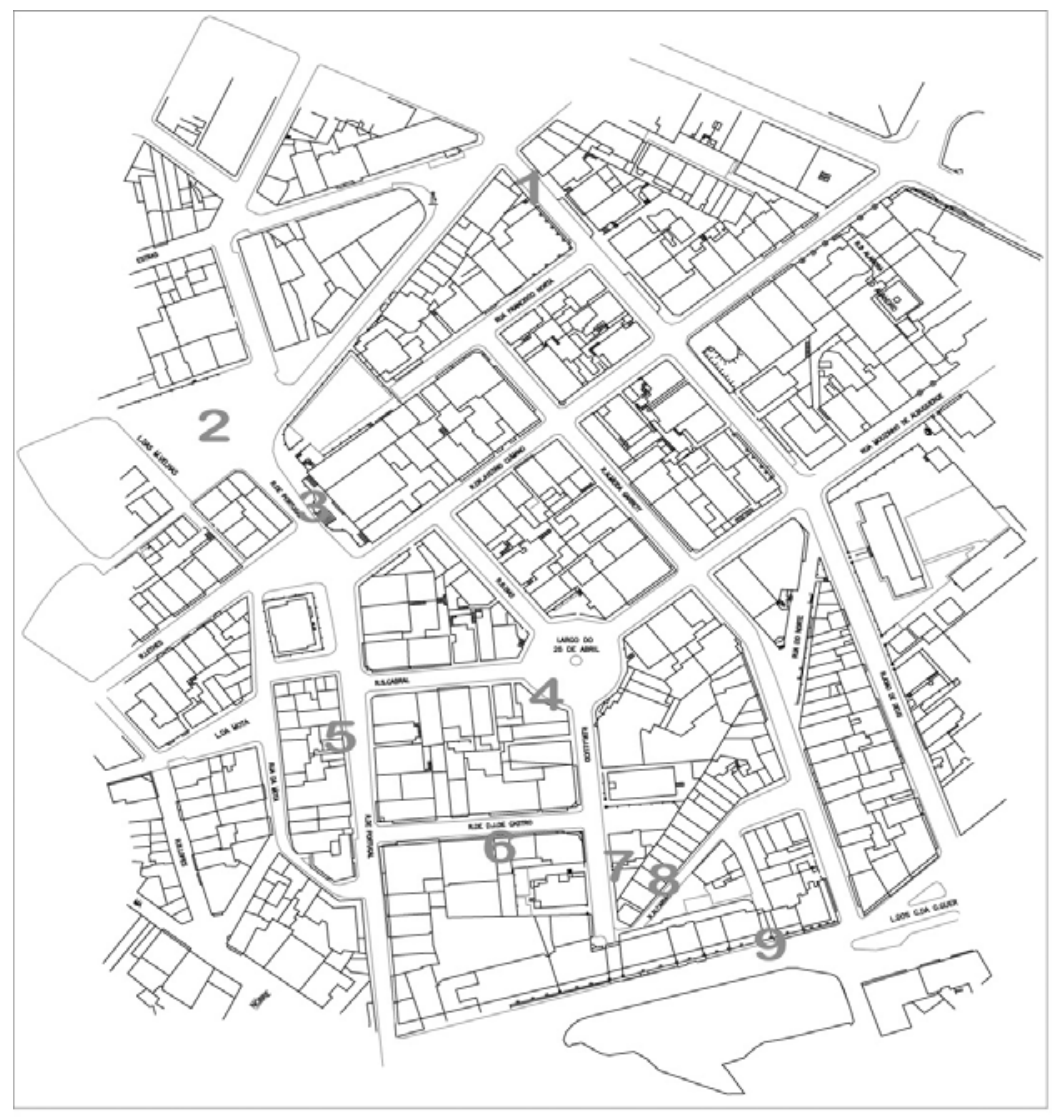

Legenda:

1 - Rua João de Deus

2 - Largo das Mouras Velhas

3 - Teatro Lethes

4 - Largo 25 de Abril

5 - Rua de Portugal

6 - Rua João de Castro

7 - Rua João Lúcio

8 - Rua das Alcaçarias

9 - Rua de Santo António

Figura 2. Localización de los hallazgos de enterramiento en el área de la necrópolis norte de Ossonoba.

has, que sólo cinco de ellas correspondían a incineraciones (Santos, 1971, 192, anotación 48), a las que se sumarían otras nueve documentadas en la plaza 25 de Abril $^{1}$, de las que tres contenían ajuar funerario formado por objetos de primer orden, es decir, que participaron en el proceso de incineración del cuerpo. Estos últimos "enterramientos" sin ninguna estructura de señalización, recuerdan las nueve cremaciones del tipo busta de la Plaza Ivonne Cazenave de Huelva (Vidal y Campos, 2006, 17-19).

Sin embargo, la inhumación parece la práctica más ampliamente difundida en Ossonoba, repre-

1 Algunas de estas evidencias puede que no sean enterramientos. Las tres incineraciones, que los autores no han logrado determinar si corresponden, o no, al tipo bustum, estaban bien marcadas en el terreno por fosas circulares de tierra negra con dimensiones que rondaban los $1,20 \mathrm{~m}$ por $1 \mathrm{~m}$, con carbones y huesos quemados. Su ajuar, compuesto por lucernas y cerámica común, apunta hacia una datación comprendida entre mediados del siglo I y mediados del siglo II (Teichner et. al., 2007, 166, anotación 3; 168-169 y 176). sentando más de 90\% de los casos de la necrópolis Norte (vide tabla 1). Seguramente, esta realidad se deba al hecho de que la mayoría de las tumbas halladas se fechan, a juzgar por su tipología y ajuar, en un momento bajo imperial durante el cual la inumatio era el único ritual de enterramiento. Además, parece probable que el momento de transición de un rito a otro (crematio a inumatio), tuvo lugar de una manera más tardía que en el resto de parte del imperio. No obstante, la coexistencia de ambos rituales, con predominio de la inhumación, es frecuente en toda Hispania hasta el siglo III $d$. C., como es el caso del Alentejo (Frade y Caetano, 1993). La ciudad romana de Balsa (Viana, 1952), también en el Algarve, sigue siendo una incógnita en lo referente a este fenómeno.

Las tumbas de una necrópolis, en época romana, estaban establecidas a lo largo de las vías, en ocasiones, bien organizadas a lo largo de ellas. Desafortunadamente, las limitadas dimensiones de muchas excavaciones realizadas en la necrópolis Norte de 


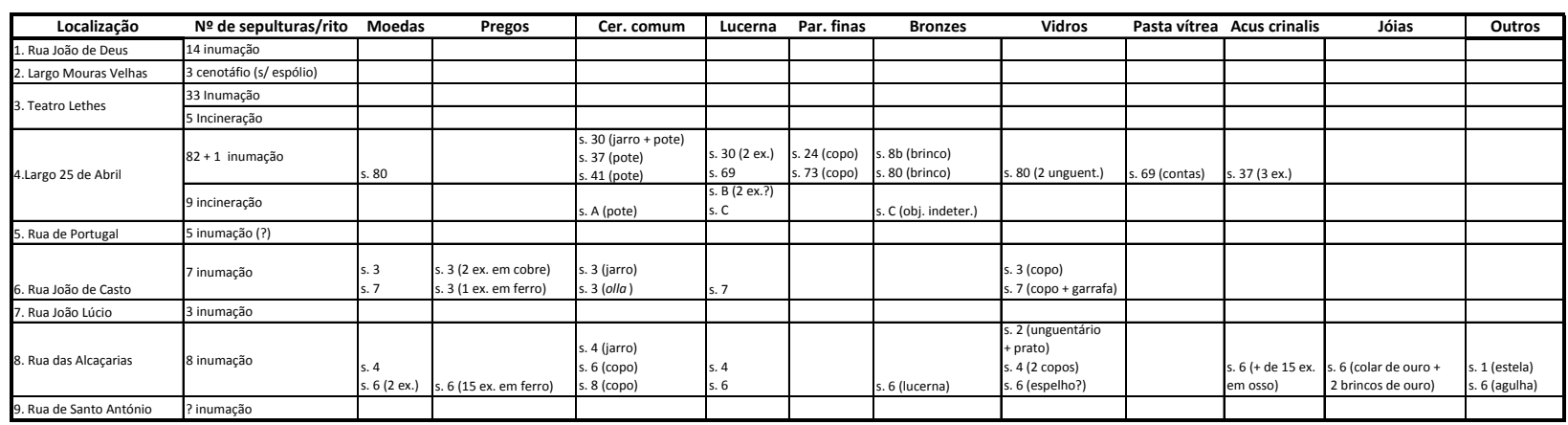

Tabla 1.

Ossonoba, o aún el carácter incipiente del registro de las intervenciones antiguas, no permiten conocer aún cómo se organizaba este espacio funerario, aunque sabemos de la existencia de diferentes tendencias y predominancias de orientación de las tumbas en las distintas áreas escavadas. En este sentido, y asumiendo que gran parte de los registros delatan orientaciones mínimamente fiables,

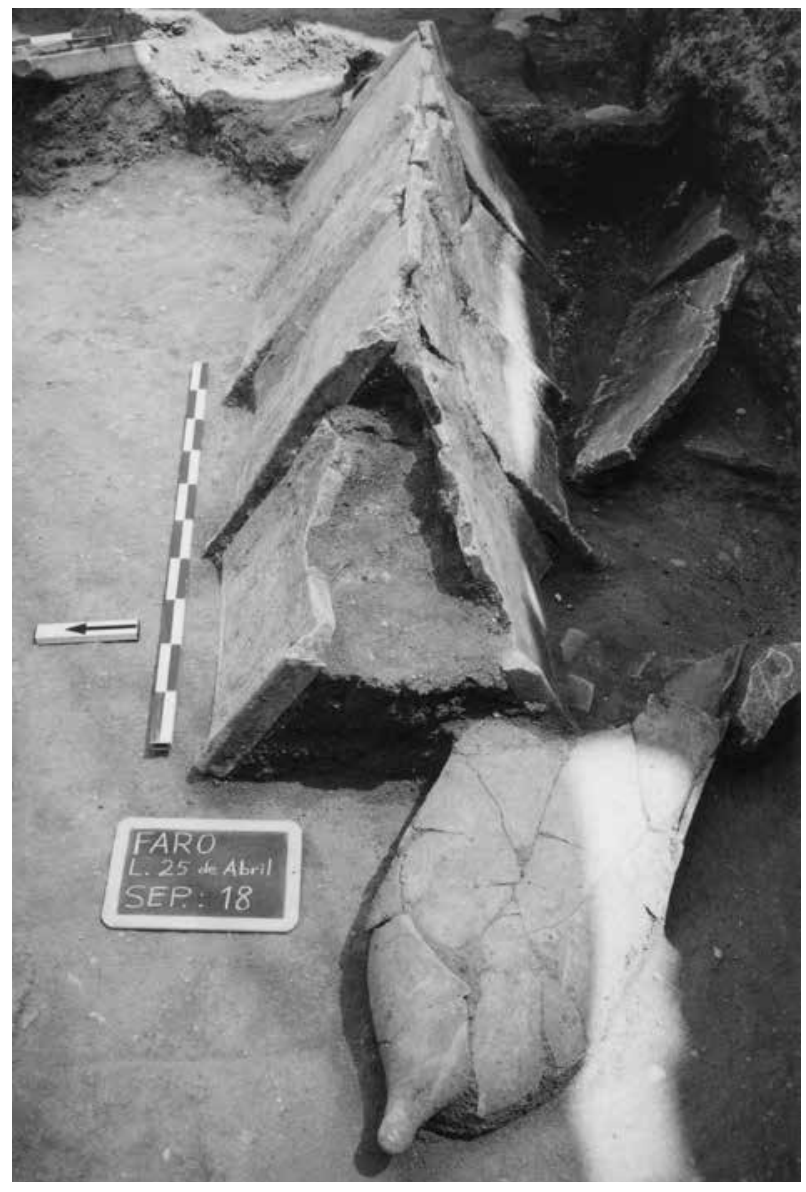

Figura 3. Sepultura de fosa con cubierta de tégulas destruida parcialmente por una inhumación en ánfora africana. en el área del barrio de Lethes los enterramientos explorados por Estácio da Veiga presentan de manera mayoritaria una orientación W-E y, en menor número, $\mathrm{Nw}$-Se. Esta última es predominante, sin embargo, en la intervención efectuada en la plazuela 25 de Abril, donde se verifican también otras orientaciones distintas, concretamente $\mathrm{Ne}-\mathrm{Sw}$, que, a su vez, es exclusiva en los enterramientos de la calle de Alcaçarias y de João Lúcio.

Las enormes áreas que las necrópolis Norte y occidental ocuparon están justificadas, a semejanza de lo que pasa en la septentrional de Onoba o en la oriental de Baelo Claudia, por una cierta intermitencia del campus funebris (Fernandez et alii, 2013: 180-181). La existencia de espacios libres entre tumbas se puede observar en el plano elaborado por Estácio da Veiga en 1878 (fig. 4), verificado por Teresa Júdice Gamito en la calle de Alcaçarias (Gamito, 1992, 101). En terrenos anexos a estos espacios vacíos se observan, a veces, áreas de gran densidad escatológica, como es el caso de los $400 \mathrm{~m}^{2}$ excavados en la plazuela 25 de Abril, donde se documentaron 91 tumbas, la mayoría en la mitad occidental, incluso superpuestas (Teichner et alii, 2007, 161, Fig. 1). Este paisaje, definido por la concentración en determinados sectores de tumbas, seguido por espacios semivacíos o vacíos, podría ser reflejo de la división del terreno en función de la existencia de diferentes collegia funeraticia o grupos diversos, tales como familiares, étnicos u otros. En este sentido, las dispares orientaciones de los cadáveres en estos mismos sectores pueden reflejar esas diferencias. Estos collegia disponían de espacios delimitados de forma visible, al igual que lo eran los jardines funerarios de los más adinerados, como en el caso de Trimalción (Petronio, Satiricon, LXXI). De estos recintos fúnebres la Arqueología ha revelado muchos testimonios en las ciudades de la vecina provincia Baetica, empezando por las inscripciones 

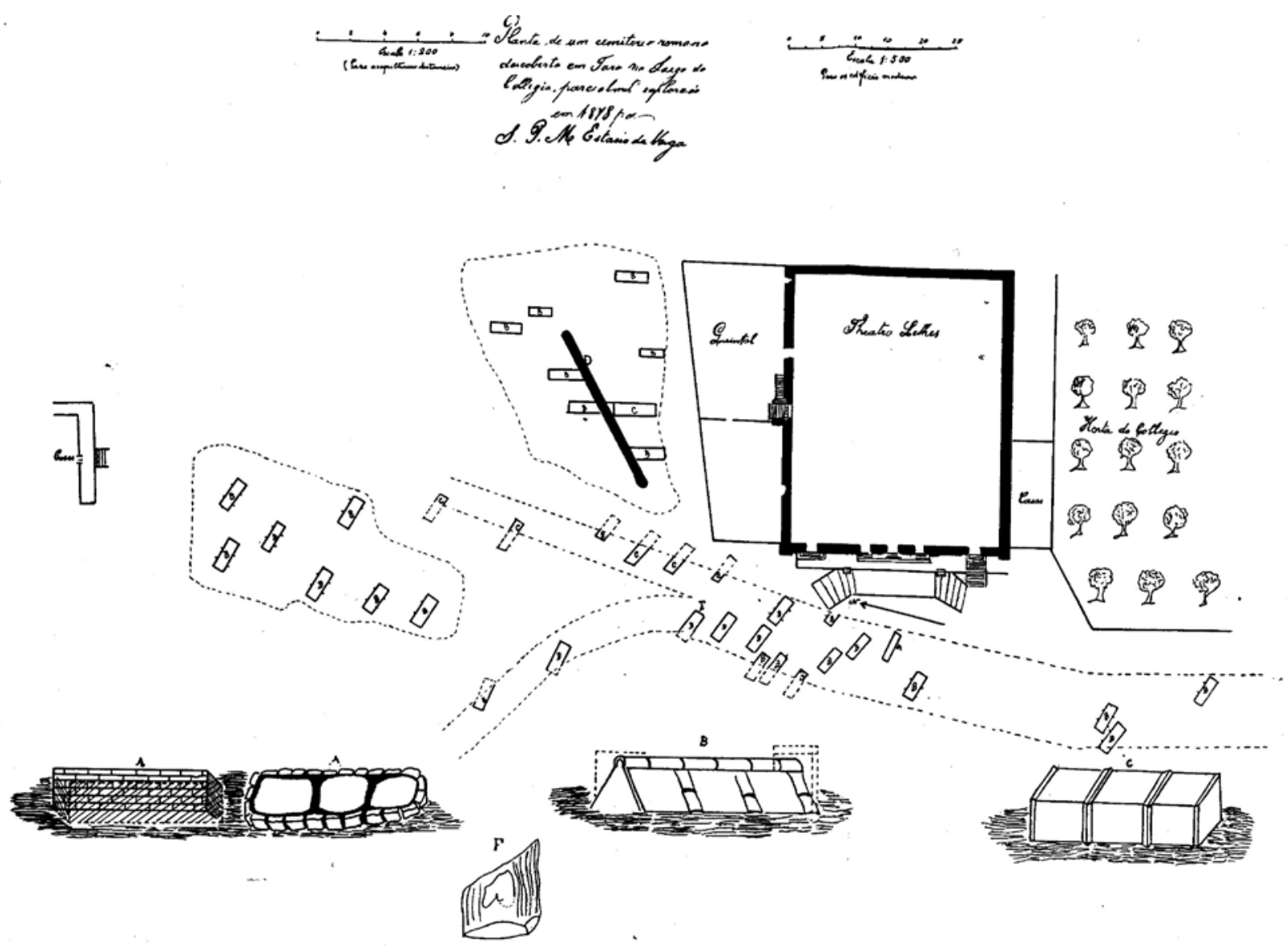

Figura 4. Levantamiento de la necrópolis excavada por Estácio da Vega en 1878 en las inmediaciones del teatro de Lethes, donde se reflejan los tres modelos de tumbas encontrados.

con indicatio pedaturae que delatan la extensión de esos espacios en Corduba (Vaquerizo Gil, 2010, 74-83) o por las propias estructuras murarias que los delimitan en el caso de la necrópolis Norte de Onoba (Fernández et alii, 2013). Desafortunadamente, en la ciudad de Ossonoba no ha sido posible, aún, identificar alguna estructura de esta naturaleza.

De las excavaciones realizadas en la principal necrópolis de esta urbe, las tumbas $\mathrm{n}^{0} 6$ de la calle de Alcaçarias y la $\mathrm{n}^{0} 7$ de la calle João de Castro, relativamente próximas, son las que presentan el ajuar más rico y variado. La calidad y diversidad del ajuar identificado (vide tabla 1), unido a la considerable complejidad de su elaboración, nos permite inferir y jerarquizar el nivel social de los inhumados, así como establecer una aproximación a la organización del espacio funerario en relación a la vía que conectaba con la ciudad. Obviamente la apariencia de las necrópolis urbanas está fundamentalmente marcada por las tumbas de los notables que tenían recursos para adquirir un locus de elevado importe, y ahí construir verdaderos mausoleos o auténticas mansiones funerarias, obteniendo, habitualmente, las parcelas mejor localizadas, es decir, las que estaban junto a las murallas y contiguas a la vía. Partiendo de esta norma, y admitiendo que los menos adinerados ocuparían plazas secundarias en la necrópolis, es admisible que las tumbas citadas inicialmente estuvieran próximas a la vía, mientras que las documentadas en la plazuela das Mouras Velhas, o las que Abel Viana $(1951,148)$ observó en el sector de la calle João de Deus antes del cruce con la Horta Machado, construidas con tegulae y ajuar más sencillo o ausente, se hallasen más lejos de la vía y de la cuidad.

Las primeras tumbas que hemos referido de las calles de Alcaçarias y João de Castro, alzadas en caja de ladrillos y con cubierta de tegulae (fig. 5), son las que presentan, hasta el momento, las estructuras de mayor calidad, con ajuares correspondientes a personajes de un alto nivel social, compuesto en el caso de la tumba $n^{0} 6$ por un collar y pendientes 


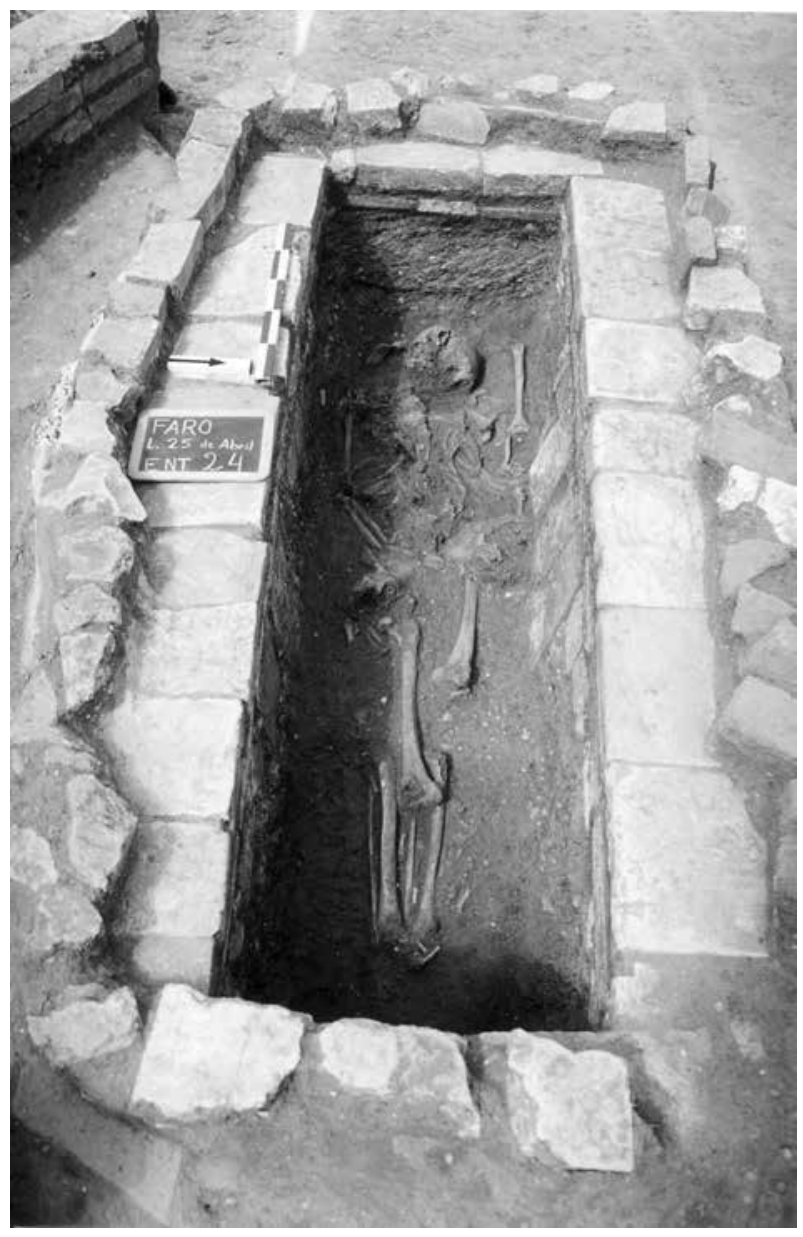

Figura 5. Sepultura en caja de ladrillo correspondiente a las sepulturas más elaboradas encontradas en Faro.

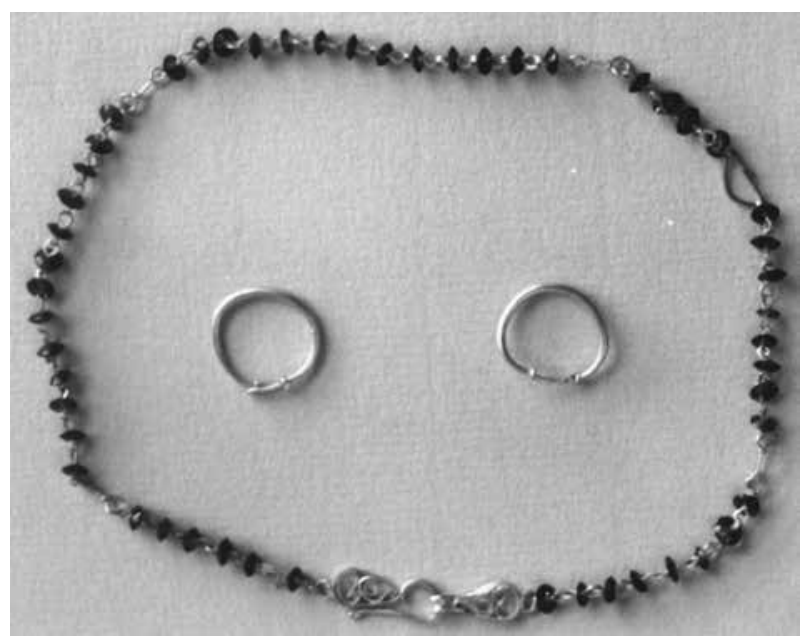

Figura 6. Collar y pendientes de oro provenientes de la sepultura 6 excavada en 1984 en la calle de Alcaçarias. de oro, una bolsa de acus acrinalis y una lucerna de bronce, y en el $\mathrm{n}^{0} 7$ por una botella de vidrio profusamente decorada (figs. 6,7 y 8 ). Es posible, por lo tanto, que la vía que cruzaba esta necrópolis, y seguía en dirección Norte, pasara por entre estas calles o próxima a ellas, considerablemente alejada de la plazuela das Mouras Velhas.

Las arqueólogas responsables de los sondeos en aquella plazuela en 2007, durante los cuales se identificarían tres tumbas, atestiguan, según la base de datos Endovéllico que "embora as suas coberturas em tégula se encontrassem, aparentemente, in situ, não se observaram quaisquer vestígios de ossos ou espólio associado aos enterramentos”. Obsérvese que la localización de estas tumbas estaría, supuestamente, en una zona periférica de la necrópolis, donde dicha ausencia de material osteológico se puede justificar por la simulación de enterramientos de individuos cuyo paradero de los restos mortales era desconocido. La interpretación de estas tumbas como cenotafios -común por todo el imperio, particularmente en ciudades litorales donde parte de la población subsistía del mar- daría sentido a la situación periférica de estas tumbas en el espacio funerario. El funus imaginarium que culminaba en el cenotafio podía estar al cargo de los familiares, al igual que de los collegia funeraticia que cumplían el contrato a que estaban obligados con el asociado que, en vida, pagaba una cuota a tal efecto (Vaquerizo Gil, 2010, 17).

Debemos aún advertir ciertas particularidades, cuya detección siempre está pendiente de la calidad del registro arqueológico, como la que ocurre en la tumba $\mathrm{n}^{\mathrm{O}} 3$, excavada en 1938 por Abel Viana (1951, 149-152), en la calle João de Castro. Dicha sepultura, en caja de ladrillos con orientación $\mathrm{Nw}-\mathrm{Se}$, contenía una inhumación de un adulto en decúbito lateral, con el cráneo dirigido al $\mathrm{Nw}$, apoyado sobre el lado derecho y con las manos unidas junto al rostro. Esta posición, poco canónica, en la que fue encontrado el inhumado podría indiciar alguna práctica cultual o religiosa, o sencillamente estar relacionada con la presencia, a los pies y bajo ladrillos, de otra inhumación infantil, donde por asimilación el individuo adulto asumiría la posición fetal del infantil. Acompañaba a ambas inhumaciones, también situada a los pies del adulto y bajo ladrillos, una olla cerámica, que a juzgar por su posición debía pertenecer al enterramiento del impúber. A la altura de las piernas del adulto fue depositado un jarro, un vaso de vidrio de base hexagonal y dos cla- 


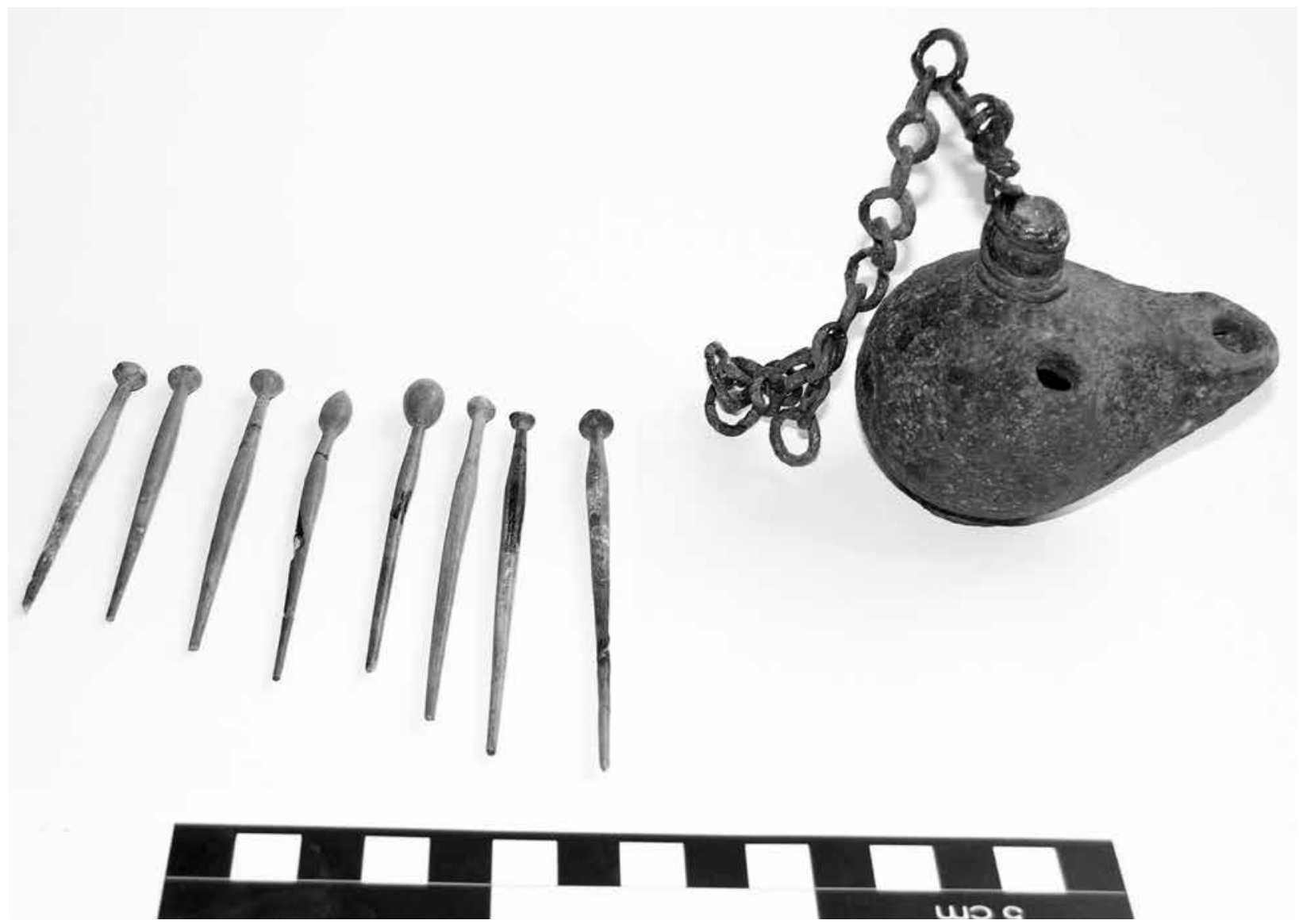

Figura 7. Alfileres de tocador de diferentes tipos y lucerna de bronce con cadena de suspensión encontrados juntos a los pies de la inhumación de la sepultura 6 excavada en 1986 en la calle de Alcaçarias.

vos de bronce, uno de los cuales aún seguía envuelto por vestigios de madera. Estos clavos, a los que se suma un tercero de hierro, podrían haber pertenecido a un objeto de madera que desconocemos. Obsérvese, no obstante, que la deposición de cajas personales de madera en las tumbas era una práctica común. Estos materiales delatan una datación para esta tumba que situamos en momentos centrales del siglo IV, admitiendo incluso que puede ser retrasada al III (Cruz, 2009, 93-95). Reflexionando sobre el ritual y deposición funeraria podría tratarse de un enterramiento paleocristiano en un momento en que la simbiosis entre rituales funerarios paganos y cristianos sería normal. El argumento que utilizamos para apoyar la propuesta lo basamos en la presencia de una jarra que es tipológicamente similar a las que acompañan, frecuentemente como único ajuar, las tumbas paleocristianas del Sudoeste peninsular a partir del siglo IV, a lo que unimos la presencia en este momento en Faro de una considerable comunidad cristiana liderada por un Obispo,

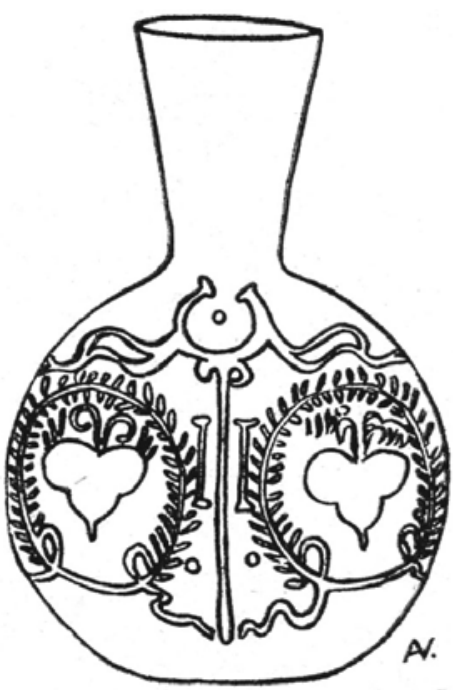

Figura 8. Diseño de una pequeña botella con grabados $(11 \mathrm{~cm}$ de diámetro máximo), perteneciente a la sepultura número 7 excavada por Abel Viana en 1938 en la calle João de Castro 
participante activo e influyente en los concilios de entonces (Jorge, 2002, 99 y ss). En cuanto a la deposición en decúbito lateral, aunque resulta poco canónica en época romana, se constata en varias necrópolis del Sudoeste peninsular, como Carmo, Astigi, Cordoba o Gades (Vaquerizo, 2010, 278).

Las tumbas de una necrópolis pueden variar entre una sencilla fosa abierta en el suelo, como las descubiertas en la villa de Milreu, o las someramente referidas por Abel Viana cerca del cruce de las calles João de Deus y Horta Machado, hasta construcciones monumentales como los grandes mausoleos que se han registrado en la ya mencionada villa, pero que siguen sin ser halladas en Ossonoba. Desde las primeras excavaciones esporádicas hechas en la ciudad en el siglo XIX por Estácio da Veiga hasta las más recientes, se constata que las tumbas son fundamentalmente de dos tipos: o bien una caja rectangular hecha de ladrillos, revestida en el interior con losas de piedra o tegulae, cubierta por éstas mismas instaladas de manera horizontal o formando un tejado a dos aguas (fig. 4); o bien, el tipo más sencillo y frecuente, consistente en una cubierta de tegulae a dos aguas sobre una fosa donde se depositaba el cuerpo (fig. 5) (Santos, 1971; Viana, 1951; Gamito, 1992). Estos dos tipos, particularmente el segundo, son los más frecuentes también en Balsa (Viana, 1952) o incluso en Andalucía (Vaquerizo, 2010), aunque no son los únicos. Además de estos, en Ossonoba se ha constatado un modelo intermedio, consistente en revestir la fosa abierta en el suelo de tegulae, con cubierta horizontal del mismo material o en tejado a dos aguas, como en el tipo 2 (cf. fig. 3). Finalmente, es posible individualizar un cuarto tipo, constatado únicamente en la intervención de la plazuela de 25 de Abril, o en necrópolis fuera de Faro como la villa de Cerro da Vila y de Horta de São Cristóvão, consistente en el enterramiento de individuos infantiles en ánforas (Teichner et alii, 2007). En la necrópolis occidental de Astigi (Écija), entre tumbas de inhumación y de incineración en cajón de ladrillos cubiertas con tegulae a doble vertiente o en fosas abiertas en el suelo, surgen frecuentes deposiciones infantiles en ánforas (Aguilar Camacho, 2004, 891-898; Ruiz Osuna, 2010, 61). Este tipo de tumbas vienen revelándose en muchos yacimientos del Sudoeste peninsular como Gades, Baelo Claudia, o la propia Onoba.

Debemos aún mencionar que en la necrópolis Sur del último yacimiento citado, así como en la plazuela 25 de Abril, en Faro, la presencia de ánforas aparece también asociada a libaciones (Vidal y Campos, 2006, 16 y 22), utilizadas como conductos que canalizan las ofrendas hasta el interior de las tumbas. En el caso portugués se cuenta con dos ejemplos definidos por dos fragmentos de ánfora situados en la parte superior de la cubierta de tegulae, únicos ejemplos documentados y publicados hasta el momento de este tipo de prácticas en el núcleo ossonobensis.

Es posible que a medida que se vayan descubriendo nuevas localizaciones pertenecientes a la principal necrópolis, se conozca una mayor variedad tipológica, similar a la del Alentejo (Frade y Caetano, 1993) o Andalucía (Vaquerizo Gil, 2010). No se descarta incluso la aparición de tumbas monumentales, dado que si bien es cierto que a día de hoy no se han constatados edificios funerarios de estas características, parece comprobada su existencia merced a la inscripción funeraria de L. Attius Nisus, donde se cita, en la formula final, la palabra Misolio, interpretada como mausoleum (Encarnação, 1984, 63-64 = IRCP 16).

\section{LAS NECRÓPOLIS DE ONOBA}

En la ciudad de Onoba, a diferencia de la de $O s$ sonoba, la mayor parte del conocimiento obtenido procede de la realización de excavaciones arqueológicas, a través de las cuales se ha logrado definir parte del paisaje funerario correspondiente a las necrópolis Norte, Sur y Este (fig. 9). Tanto la septentrional como la oriental se dispusieron a lo largo de las principales vías de comunicación de la colonia, la primera en relación con la vía 23 del Itinerario de Antonino Ab Ostio Fluminis Anae Emeritan usque, encargada de unir la zona minera con el puerto, y la segunda con la existente entre Onoba y Hispalis. Algo diferente es el caso de la necrópolis meridional al quedar reducida espacialmente al saliente mareal de este extremo de la ciudad. Esta marginación, contraria al concepto romano de necrópolis como escenario de representatividad, podría ser entendida si sus edificaciones hubiesen sido dispuestas de tal manera que su monumentalidad pudiese ser apreciada desde el mar por parte de los comerciantes que llegaran a la ciudad. Pese a ello, la escasez de restos constatados, así como su pésimo estado de conservación, impiden confirmar esta interpretación.

Del análisis conjunto de todas estas necrópolis se puede inferir que únicamente la septentrional con- 
tó con una ocupación efectiva en época republicana (siglos II-I a.C.), caracterizada por la presencia de enterramientos de incineración en fosa carentes de ajuar, asociados a una estructura muraria probablemente perteneciente a un recinto funerario.

Hacia el cambio de Era, de la mano del crecimiento económico y la consecución del estatuto de colonia (Campos et alii, 2010, 67), se producirá una importante revolución funeraria, materializada en la ocupación de los suburbios meridional y oriental, así como en la ejecución de un importante programa arquitectónico. Paralelos de este despegue edilicio se documentan en otras ciudades del sureste hispánico, concretamente en Corduba y varias poblaciones localizadas en el alto Guadalquivir, caso de Castulo, Iliturgi, Salaria, Ossigi, Tucci y Urgavo, donde el proceso de colonización/municipalización emprendido por Roma ante el interés de controlar y administrar las riquezas mineras, favoreció la planificación de grandes empresas constructivas destinadas a la monumentalización de las principales vías funerarias, sufragadas por una importante oligarquía local que importaría los modelos sepulcrales itálicos de época tardorepublicana (Beltrán Fortes, 2000, 114; 2002, 233 y ss.; Ruiz Osuna, 2005, 80).

El paisaje funerario de las necrópolis altoimperiales de Onoba refleja una imagen exterior monumental basada en patrones heredados de la tradición romana, tales como los recintos funerarios o los monumentos de planta circular, para hundir en sus creencias más profundas una ritualidad mucho más personal e íntima, cargada de matices surgidos tras los contactos entre el horizonte cultural previo y las costumbres romanas, como la coexistencia de incineraciones e inhumaciones durante los siglos

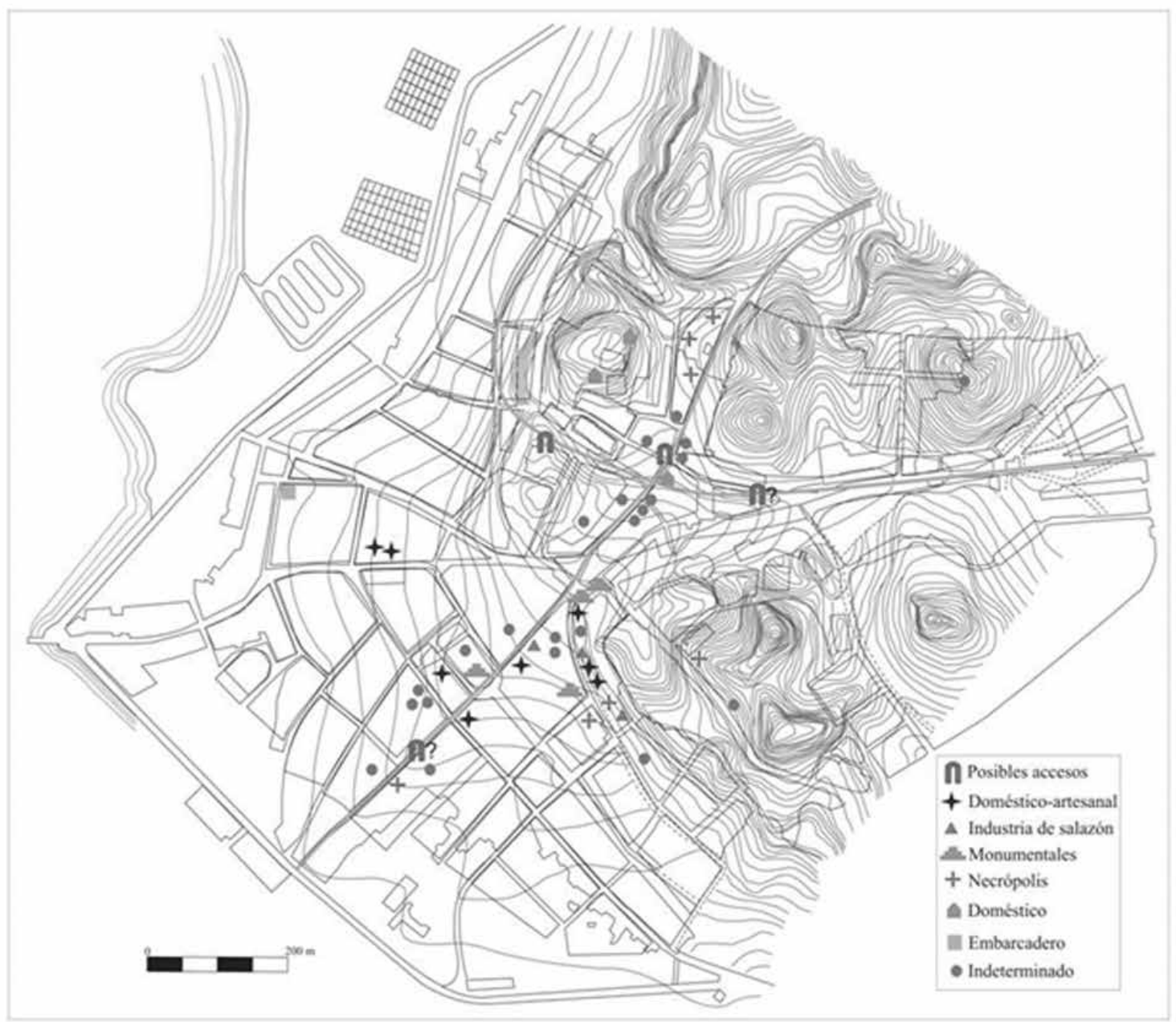

Figura 9. Áreas de la ciudad de Huelva donde se han documentado sepulturas romanas correspondientes a las tres necrópolis documentadas (Campos Carrasco, 2011, 105, fig. 57). 

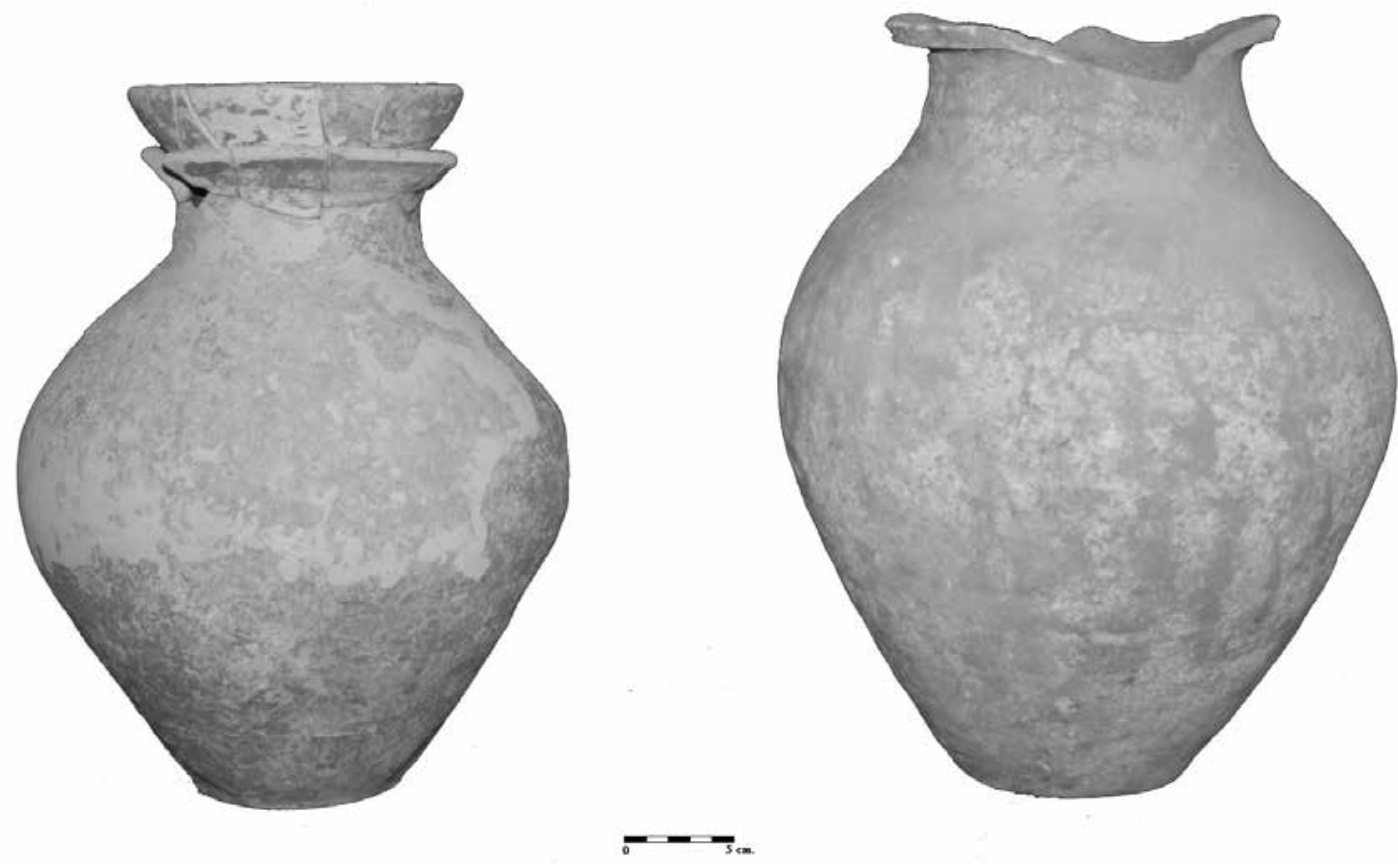

Figura 10. Urnas de tradición indígena recuperadas en el Cabezo de la Esperanza.

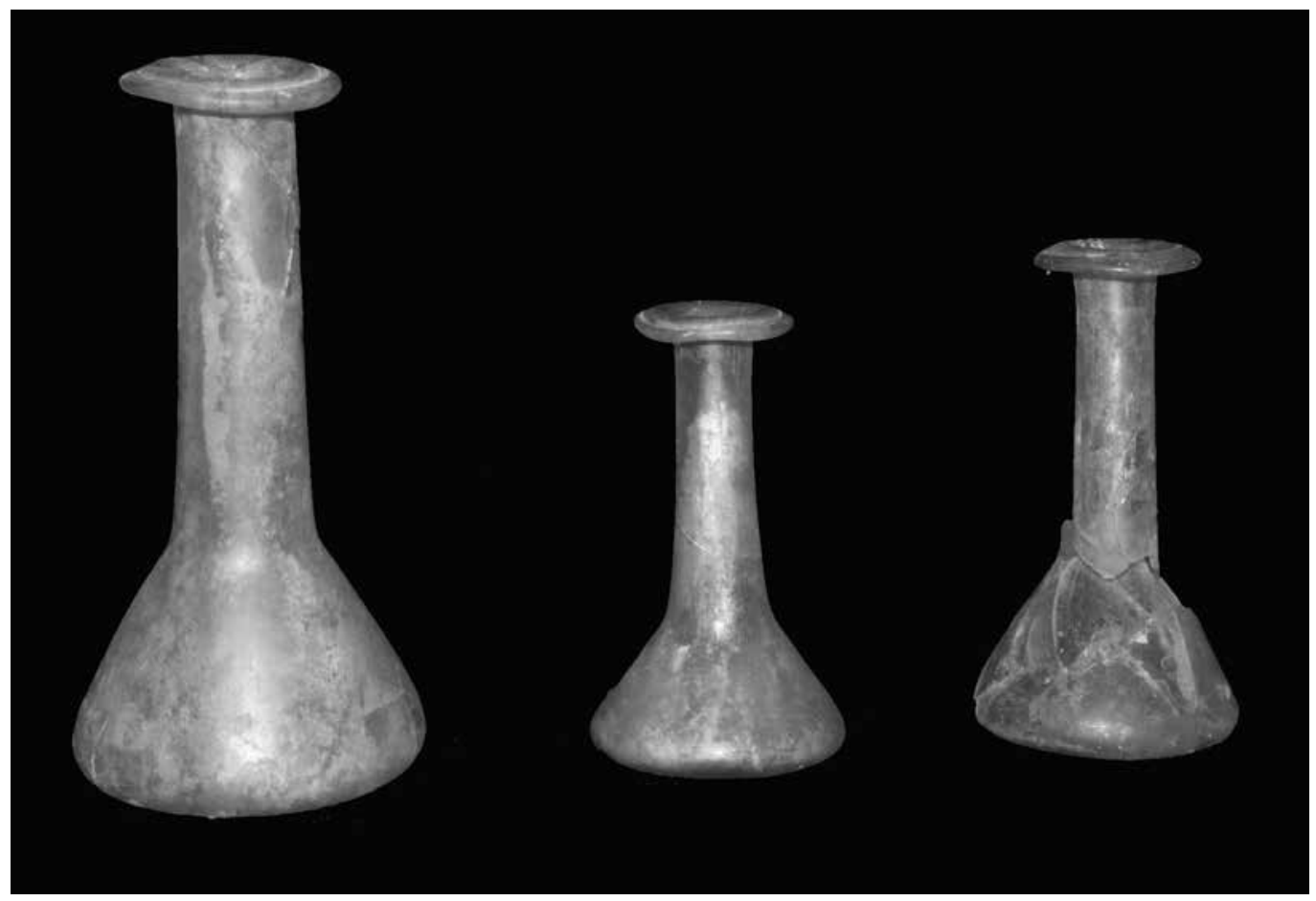

Figura 11. Ungüentarios de vidrio recuperados de una tumba bajo cubierta de tégulas de la necrópolis Este. 
altoimperiales, la práctica inexistencia de epigrafía en la ciudad, así como la exclusión consciente de sus ajuares de una pieza tan significativa como era en el momento la terra sigillata, sustituida por imitaciones en cerámica común y objetos de adorno personal, más próximos a la tradición púnica detectada en necrópolis como la de Carmo, Baelo Claudia o Gades.

Ya en época bajoimperial, la crisis del modelo económico supondrá una importante contracción de las necrópolis en dirección a la ciudad. En el caso de la septentrional, las sepulturas comenzarán a amortizar el espacio que anteriormente debió ser ocupado por los enterramientos altoimperiales, mientras que la meridional y la oriental, pasarán a ocupar el denso entramado de instalaciones industriales subsidiarias del puerto. A este importante retroceso, se le une un cambio en los patrones estilísticos e ideológicos de las sepulturas. La paulatina instauración del cristianismo, y por ende, del rito de la inhumación, favorecerá la imposición de una nueva tipología sepulcral consistente en la caja rectangular de ladrillos, tégulas o pizarras, con ajuares enormemente mermados en cuanto a número de piezas.

A nivel individual fue la necrópolis oriental la primera en ser descubierta gracias a los hallazgos del párroco local Baldomero de Lorenzo y Leal, quien pudo identificar una sepultura de época romana compuesta por una urna cineraria asociada a varios ungüentarios a espaldas del templo de San Francisco (Lorenzo y Leal, 1983).

Un siglo después las lluvias torrenciales revelarían la existencia de una nueva urna funeraria con cuenco tapadera en la zona baja del Cabezo de la Esperanza. Ésta fue depositada en el interior de una fosa cubierta por pequeñas lajas de pizarra y algunos fragmentos de cuarzo. En el análisis crítico, sus investigadores hicieron especial hincapié en el arcaísmo de las piezas, planteando una datación cronológica errónea entre los siglos IV-III a. C. en función de los paralelos establecidos con la necrópolis de Alcácer do Sal, así como en la recuperación de cerámicas a mano en sus alrededores (Garrido y Orta, 1966, 214).

Años más tarde, Mariano del Amo llegaría a contabilizar un total de cuatro cremaciones más en este cabezo. De manera indirecta, tuvo noticias de la recuperación de una nueva urna en las proximidades de la "Vía Paisajista", en el entorno de la constatada el siglo anterior (1976, 87), a la que se sumaría la documentada por él mismo durante el desmonte de parte del cerro, consistente en una urna con pequeño plato tapadera (fig. 10) (1976, 83). De tipología diferente resultan las otras dos tumbas constatadas, al tratarse de incineraciones bajo cubierta de tégulas. De ellas, sólo una aportó un ajuar compuesto por tres ungüentarios de vidrio azulado correspondiente al tipo $28 \mathrm{~b}$ de Isings (fig. 11), varios fragmentos de un vaso y una moneda de bronce con efigie de Tiberio y leyenda DIVI.AVG.F.AVG. (Amo y de la Hera, 1976, 87). Su datación se establece en época Claudio-neroniana hasta Vespasiano.

Junto a estos enterramientos se documentaría un ustrinum de $4 \mathrm{~m}$ de diámetro y $0,40 \mathrm{~m}$ de espesor, de entre cuyas cenizas se pudieron recuperar varios clavos de bronce e hierro de diversos tamaños, así como pequeños fragmentos de vidrio (Amo y de la Hera, 1976, 88).

En época bajoimperial, todas las evidencias parecen indicar que esta necrópolis comenzó a retroceder hacia la ciudad. Los restos constatados hablan de la existencia de dos sepulturas en la calle Palos, una de ellas sin excavar por encontrarse embutida en el perfil, y la otra perteneciente a una incineración bajo cubierta de tégulas en horizontal datada entre los siglos II-III d.C. En su interior se contenían los restos de un individuo infantil de unos 12

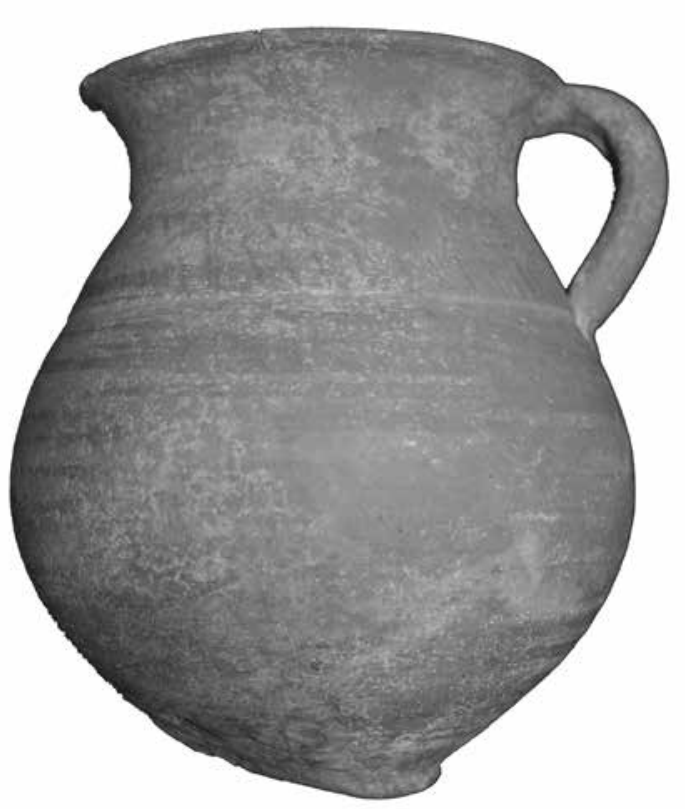

Figura 12. Elementos de ajuar correspondientes a las sepulturas de la necrópolis Sur. 
años, al cual le acompañaba un ajuar compuesto por instrumentos de cirugía colocados a la altura de la cabeza, así como una moneda no publicada (Osuna Ruiz, 1998, 11). Asimismo, en uno de los seguimientos practicados a lo largo de esta calle con el objeto de cambiar la red de saneamiento, se constató una estructura de tégulas correspondiente posiblemente a una sepultura que no se llegó a excavar (González et alii, 2001, 30).

La necrópolis meridional, localizada a lo largo de la c/Vázquez López, estuvo definida en época altoimperial por un conjunto de sepulturas de incineración bajo cubierta de tégulas. Algunas de estas tumbas contaron con conductos libatorios consistentes en un cuello de ánfora Beltrán IIB invertido, de cuyo interior se pudieron recuperar restos óseos de diferentes especies y caracoles procedentes de los banquetes o silicernia celebrados en el exterior de las tumbas. Sus ajuares estuvieron compuestos fundamentalmente por objetos de vidrios- ungüentarios y vasos-, combinados en algunos casos con piezas cerámicas, y en otros con elementos de adorno personal (fig. 12) (Castilla et alii, 2004, 506 y ss). Todas ellas fueron practicadas hacia mediados del siglo I d.C. con orientación noreste-suroeste, igual a la que poseían las estructuras funerarias ubicadas en sus proximidades ${ }^{2}$ (González et alii, 2001, 30; López et alii, 2005, 35).

En época bajoimperial esta necrópolis experimentará una importante contracción. Los restos documentados se limitan a una posible cremación y una inhumación, ambas practicadas sobre el espacio que en época altoimperial fue destinado al establecimiento de instalaciones portuarias. La incineración en cuestión se encontraba en muy mal estado de conservación, de ahí que sólo se pudiera constatar parte del derrumbe de su cubierta, así como el nivel de cenizas correspondientes a la cremación (Castilla et alii, 2001, 13; 2004, 517). Por el contrario, la inhumación se hallaba prácticamente intacta, conformada por un cuerpo de tégulas dispuestas en posición horizontal (fig. 13). Bajo éste se localizó una doble deposición, consistente en una mujer y un neonato de entre 1 y 2 semanas de vida extrauterina, posiblemente una madre y su hijo, como así parece evidenciar la posición del niño entre las pier-

2 De estas estructuras sólo se nos han conservado parte de sus fachadas, consistentes en muros de mampostería en muy mal estado de conservación. La inexistencia de excavaciones imposibilita que podamos conocer qué tipo de enterramientos y acciones rituales se practicaron en su interior. nas como si se tratara de un alumbramiento (Mora Rodríguez, 2005, 92).

La última necrópolis constatada se localiza en la zona septentrional, concretamente en la vaguada que conforman los cabezos de Mondaca, San Pedro y el Pino, entre la Plaza Ivonne Cazenave y la de San Pedro. Al margen de su fase republicana, ya comentada a inicios de este apartado, es su despegue edilicio hacia el cambio de Era, el que la convierte en el camposanto más monumental de todo el paisaje funerario de esta ciudad.

La construcción que por antonomasia destaca en esta necrópolis es el edificio sepulcral de planta circular localizado en el solar de la Plaza San Pedro, similar a los numerosos edificios de cuerpo cilíndrico de menos de $7 \mathrm{~m}$ de diámetro que florecieron por toda la Península Itálica durante el siglo I d.C. (Sacchi, 2003, 157), precisamente tras la elección de $\mathrm{Au}-$ gusto de esta tipología monumental como sepultura (Zanker, 1992; Vaquerizo Gil, 2002, 181). Se trata de una estructura circular de 3,6m de diámetro por $2,5 \mathrm{~m}$ de altura conservada, en la que se emplearon mampuestos de pizarra con ladrillos, sillarejos de calcarenita, tégulas y mortero de cal (fig. 14) (González y Guerrero, 2008, 265). Su cámara funeraria estuvo revestida de mortero de cal con pintura roja, coronada por una cúpula de opus signinum asentada sobre una aproximación de hiladas de lajas de pizarra (González y Guerrero, 2008, 266).

Enfrentado a este sepulcro, en sentido norte-sur, se articuló un conjunto de tres recintos funerarios de opus incertum, con una vida funcional comprendida entre el cambio de Era y finales del siglo I d.C., destinados a la deposición de enterramientos de cremación directamente sobre el suelo, acompañados de una intensa actividad ritual (Fernández et alii, 2013, 181).

Este programa edilicio consiguió que justo a la salida de la ciudad se contara con un paisaje funerario monumental, perfectamente articulado. A pesar de ello, las necesidades de crecimiento de la ciudad desembocarían en una revalorización urbanística de este suburbium, el cual vería como sus estructuras eran amortizadas hasta nivel de cimentación con la finalidad de construir en su lugar un establecimiento industrial. Este fenómeno no resulta exclusivo de Onoba, de hecho en otras ciudades hispanas como Corduba, la construcción de numerosos vici junto a las principales vías de acceso a la ciudad en época flavia, supusieron la amortización de importantes sectores funerarios (Vaquerizo Gil, 2002, 151), al- 


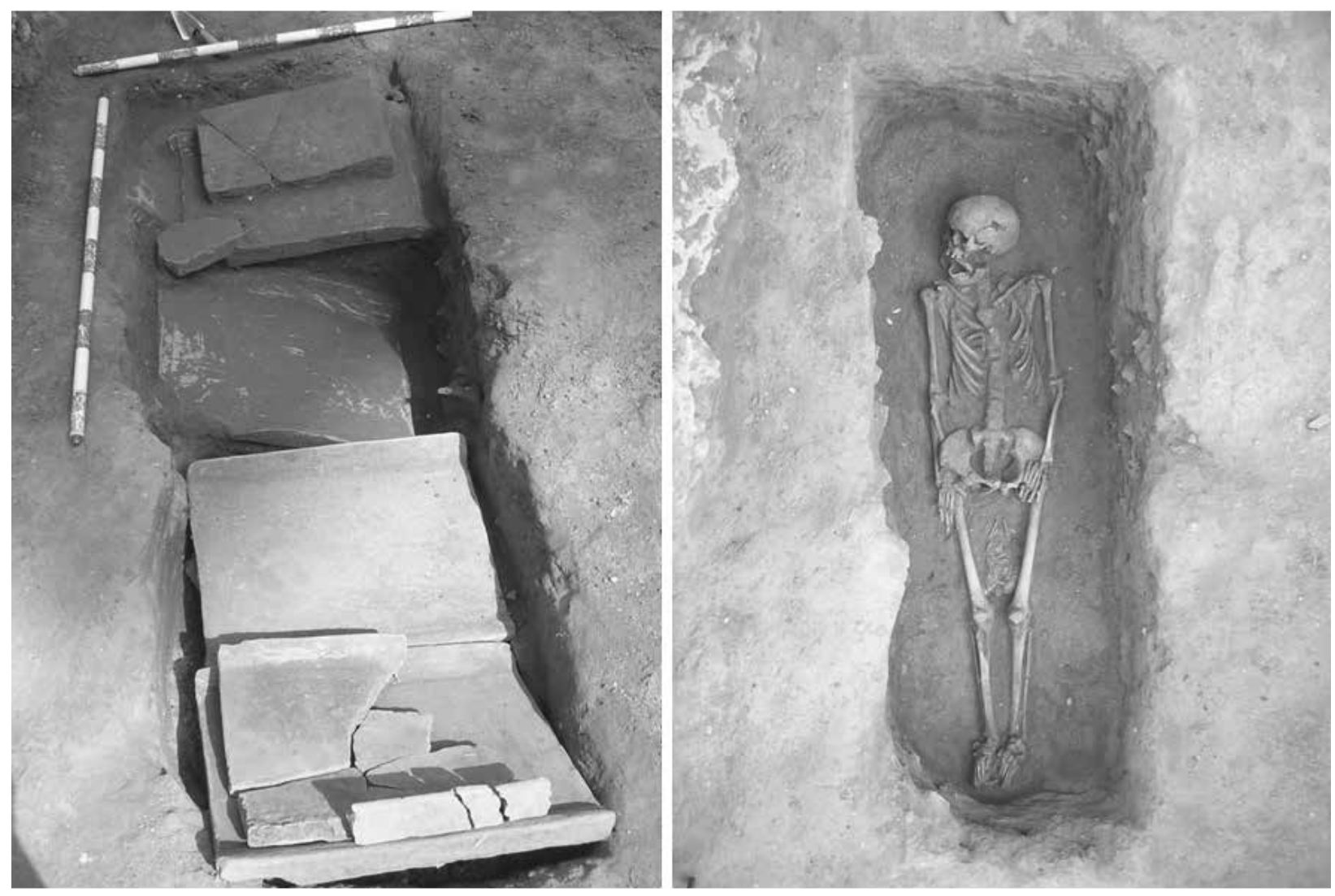

Figura 13. Inhumación bajo cubierta de tégulas de un individuo adulto femenino y otro infantil (Foto original de la empresa de arqueología G.I.R.H.A.).
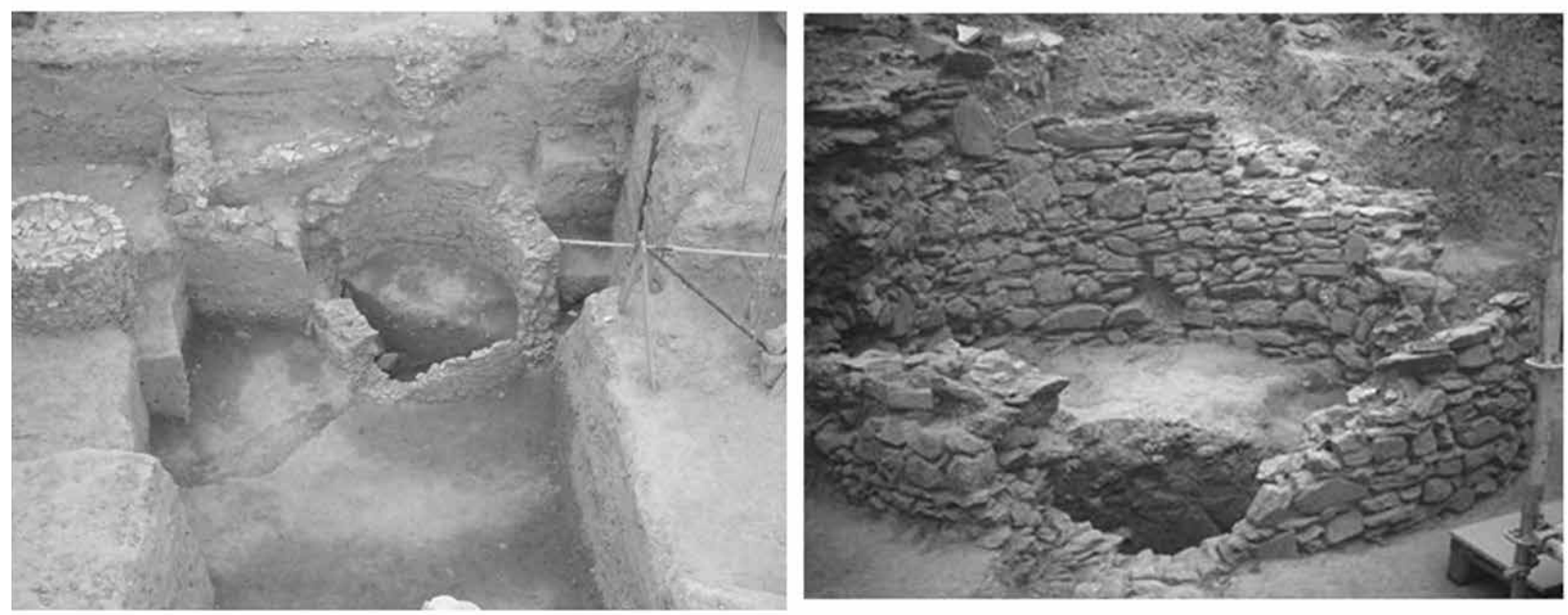

Figura 14. Monumento funerario circular altoimperial del solar de la calle San Pedro (Foto original de la empresa de arqueología ÁNFORA). 

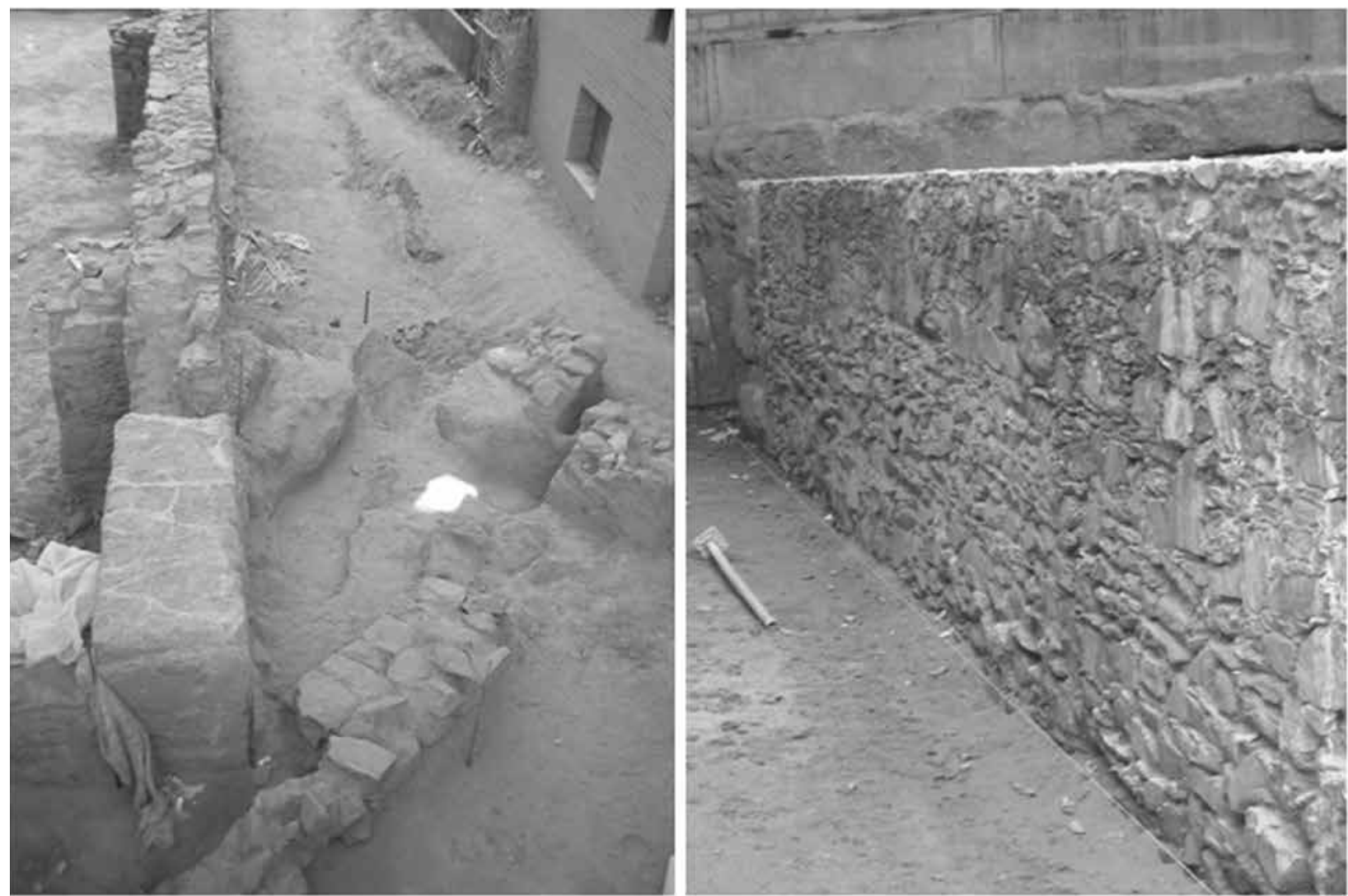

Figura 15. Acotado del sepulcretum norte constatado en la Plaza Ivonne Cazenave (Foto original de la empresa de arqueología G.I.R.H.A.).
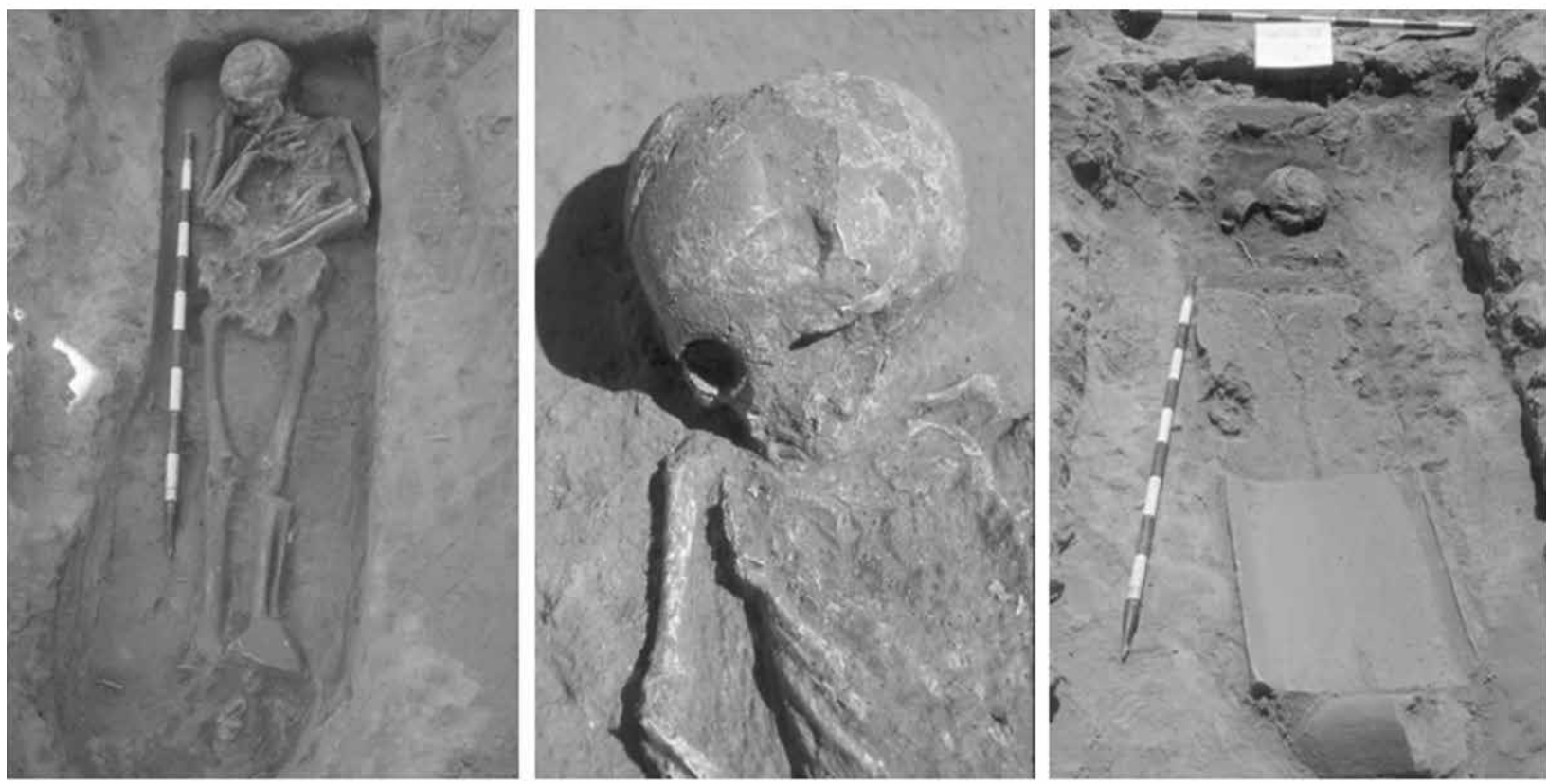

Figura 16. Sepulturas de inhumación constatadas en el interior del acotado. 

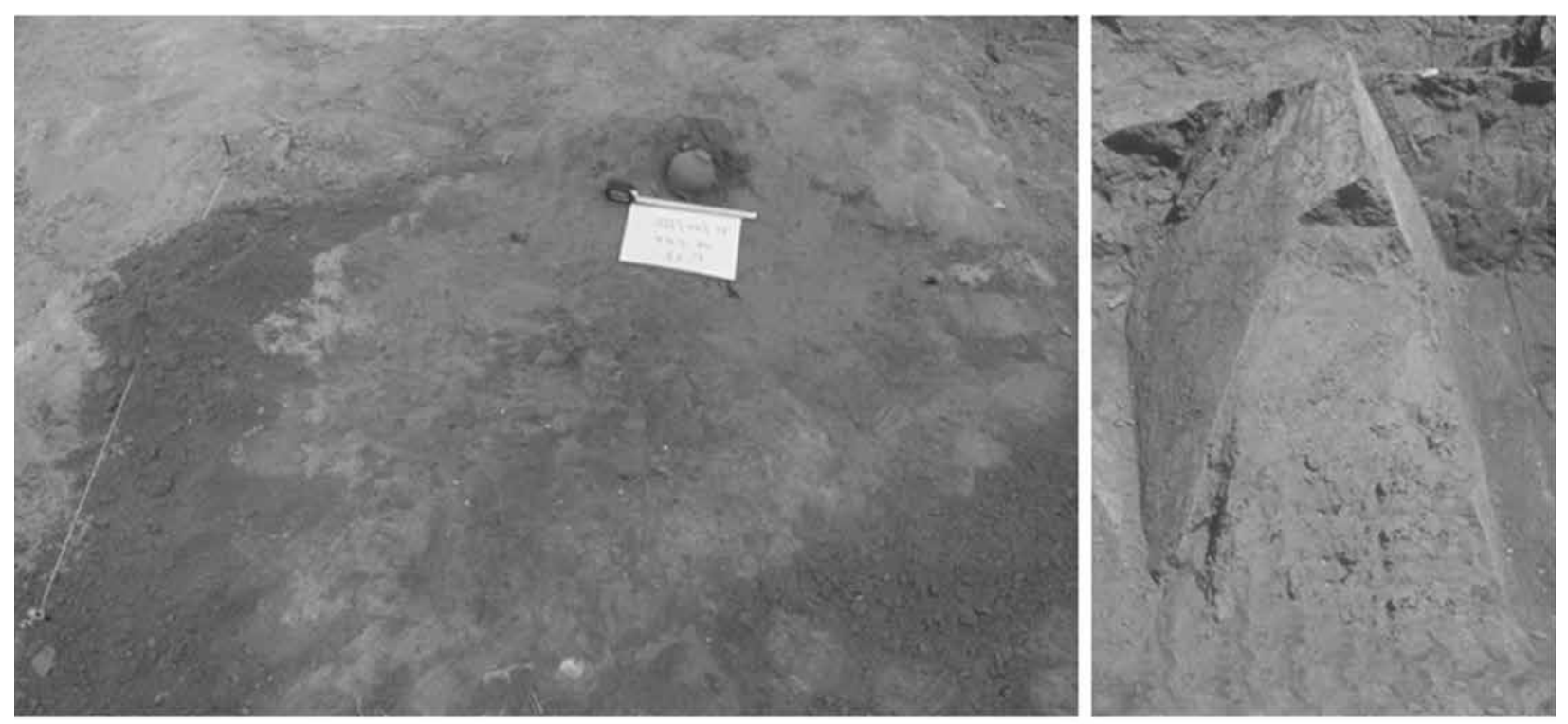

Figura 17. Sepulturas de cremación practicadas en el interior del acotado.

gunos de cuyos monumentos fueron desmontados, tapados o incluso integrados en las nuevas construcciones (Vaquerizo y Murillo, 2010, 476). Igualmente, en Emerita Augusta los importantes cambios urbanísticos generados ante la necesidad de crecimiento de la ciudad, conllevaron la anulación de las áreas funerarias más próximas a sus murallas, destacando el caso de los Columbarios, amortizados por el propio vertedero de la ciudad (Márquez Pérez, 2006, 147-148).

En el otro extremo de la necrópolis (Plaza Ivonne Cazenave), este proyecto arquitectónico conseguiría articular el paisaje funerario en torno a la existencia de varios recintos, a los que se sumaría una importante construcción, con más de $41 \mathrm{~m}$ de fachada, destinada a proteger el sepulcretum de las arrolladas constantes procedentes de los cabezos.

Los recintos de esta zona aportaron una importante cantidad de evidencias procedentes de actividades rituales, pero ni un sólo enterramiento (Fernández et alii, 2013, 184). Éstos pudieron consistir en cremaciones en urnas $u$ otro tipo de contenedores portátiles depositados directamente sobre el suelo, lo que facilitaría su posterior expolio y reutilización una vez abandonado el edificio (Vaquerizo Gil, 2010, 363)3. Como excepción, sólo el más septentrional, albergaba en su interior uno de los enterramientos más suntuosos de esta necró-

3 En relación con la existencia de posibles contenedores portátiles se encuentran las urnas de calcarenita recuperadas de la cimentación de una de las construcciones bajoimperiales. polis en cuanto a tipología y ritual (Fernández et alii, 2013, 184), posiblemente por el deseo expreso del difunto de hacerse destacar entre el resto de los individuos enterrados en este sector.

Según los restos constatados, estos edificios debieron ser construidos en época republicana, para alcanzar su momento de mayor esplendor entre mediados del siglo I d.C. principios del II d.C., fecha a partir de la cual serían abandonados y amortizados como consecuencia de la construcción de uno de los ramales del acueducto que abasteció de agua a la ciudad (Fernández et alii, 2013, 184). Las dimensiones de uno de ellos, superiores a las documentadas en otros acotados existentes en Hispania $\left(80 \mathrm{~m}^{2}\right)$, lo convierten en un caso excepcional (Rodríguez Neila, 1991, 77), concebido o bien como un cementerio público en sí mismo, dentro del cual se distinguirían secciones más pequeñas de enterramiento (Purcell, 1987, 38), o como el terreno adquirido por una familia de gran poder económico o un collegia, destinado en el primer caso a cobijar las sepulturas de todos sus miembros, incluidos esclavos y libertos, y en el segundo a todos sus socios (Donati, 1965, 94).

Junto a estas estructuras se alzaría un acotado de grandes dimensiones con el fin de acondicionar y proteger su espacio interior de cara a la práctica de sepulturas directamente sobre el suelo (fig. 15). Las primeras deposiciones, inhumaciones bajo cubierta de tégulas, fueron practicadas entre mediados del siglo I d.C. mediados del II d.C., asociadas espacialmente a un estructura de sillares de morfología 
piramidal $^{4}$ (fig. 16) (Gómez et alii, 2003, 658; De Haro et alii, 2006, 583). Con el cambio de centuria ambos ritos funerarios pasan a coexistir, si bien, mientras que las inhumaciones se siguen practicando en el mismo espacio, las incineraciones se organizan en torno a dos áreas funerarias diferenciales según el poder económico de la persona finada (fig. 17). Todos sus ajuares estuvieron constituidos por piezas de cerámica común; en ocasiones imitaciones de paredes finas; lucernas, ungüentarios, y de manera destacada, elementos de adorno personal (Fernández et alii, 2013: 183).

En época bajoimperial, concretamente hacia mediados del siglo II d.C., tendrá lugar la última gran remodelación constructiva de esta necrópolis, consistente en la edificación de un nuevo acotado funerario algo más al sur que el anterior, precedido por un monumento de sillares de planta circular. Ésta última sepultura monumental cuenta con un cuerpo principal de sillares de calcarenita dispuestos a soga y tizón con un díámetro de $4,50 \mathrm{~m}$, rodeada a nivel de cimentación por un potente anillo de materiales constructivos (fig. 18) (De Haro et alii, 2006, 581).

En el nuevo acotado se practicarán enterramientos directamente sobre el suelo entre finales del siglo II y el IV d.C. A nivel tipológico estuvieron caracterizados por una continuidad de los modelos de época altoimperial, a los que se unirán nuevas formas como las cajas de ladrillos o pizarras, y los enterramientos infantiles en ánfora. En cuanto a su ritualidad, es posible observar una paulatina sustitución del rito de la cremación, mayoritario hasta mediados del siglo III d.C., por el de la inhumación. Este cambio vendrá de la mano de una notable reducción del número de piezas incluidas en los ajuares, limitadas a partir de este momento a los denominados jarros tardoantiguos o visigodos, así como algún objeto de uso personal (Gómez et alii, 2003, 658; De Haro et alii, 2006, 582 y ss; Amo y de la Hera, 1976, 92 y ss).

4 Una estructura de similares características a ésta fue documentada en el solar de la c/ San Andrés n5 y c/Plácido Bañuelos nº 4-6 (Fernández, Rodríguez y García, 2001). No obstante, lo reducido del área de intervención, unido a la no identificación de esta estructura por sus excavadores, impidieron conocer la posible existencia de tumbas en su área próxima. Sin embargo, su ubicación unida a la anterior marcan el margen oriental de la vía sepulcral que debió cruzar esta necrópolis.
V. LAS NECRÓPOLIS DE OSSONOBA Y ONOBA: AFINIDADES ENTRE CIUDADES VECINAS DE PROVINCIAS DIFERENTES

Los datos que se conocen sobre las necrópolis de Ossonoba pertenecen, como se ha visto, a hallazgos ocasionales que no fueron debidamente registrados, y más recientemente, a excavaciones de salvamento casi siempre no publicadas o deficientemente divulgadas. Este panorama es, pues, poco alentador cuando se pretende trazar un esquema global sobre el paisaje funerario de esta ciudad romana del sur de Portugal, y menos aun cuando se pretende compararlo con lo que se conoce de otras ciudades antiguas. Esta insuficiencia en la investigación explicaría por qué no ha sido identificada ninguna estructura funeraria monumental del tipo de las constatadas en otras ciudades marítimas, caso de Onoba o Baelo Claudia, pese a que se sabe por la epigrafía recuperada, y por los mausoleos templiformes existentes a lo largo del territorium Ossonobensis, como los de la villa romana de Milreu o el del establecimiento marítimo del Cerro da Vila (Teichner, 2008, 240-245 y 403-406), que debieron existir en las necrópolis de esta ciudad.

Otra notable ausencia, en este caso en la ciudad de Onoba, es la epigrafía, ampliamente constatada por contra en Ossonoba, donde se tiene un importante conocimiento de las familias que habitaron esta ciudad del Algarve gracias a su rica epigrafía funeraria. Aun cuando rara vez han sido encontradas in situ (sólo un caso en la calle Alcaçarias de la necrópolis Norte), aportan testimonios inequívocos de los ossonobenses y de su estatus social, frecuentemente ligado al comercio.

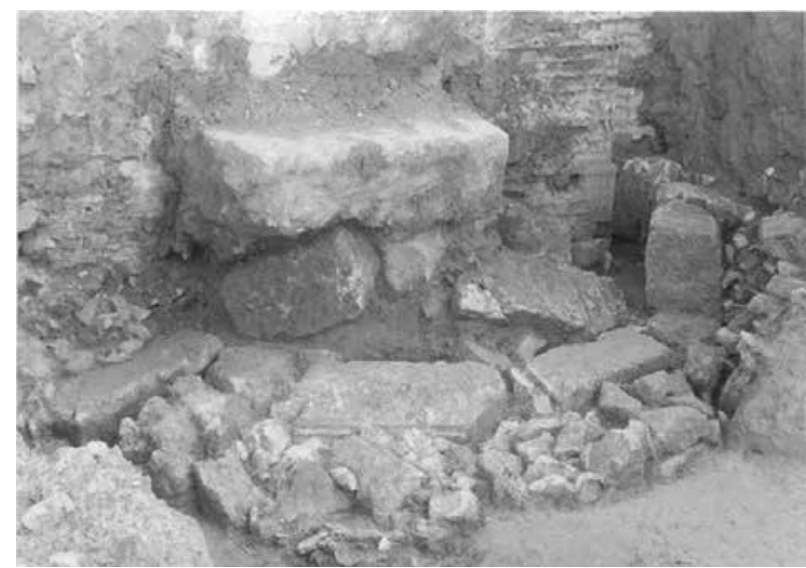

Figura 18. Monumento circular bajoimperial de la Plaza Ivonne Cazenave (Foto original de la empresa de arqueología G.I.R.H.A.). 
Al margen de estas manifestaciones, existen ciertas expresiones relacionadas con el tema de la ritualidad y tipología sepulcral que parecen incidir en la presencia de un mismo universo cultural, que integrado en la turdetania, abarcaría todo el Golfo de Cádiz, con unos patrones socioeconómicos marcados por fuertes influencias púnicas y norteafricanas (Encarnação, 1984; Viegas, 2011a; 2011b; Fernández et alii, 2013, 183). Más allá de las estructuras monumentales, el tipo de sepultura más difundido en ambas ciudades es la cubierta de tégulas a dos aguas, sucedido por las cajas de ladrillos y los enterramientos en ánfora (figs. 5 y 6) (Vidal y Campos, 2006; Vaquerizo Gil, 2010; Fernandez et alii, 2013, 183). Éstas sepulturas fueron distribuidas a lo largo de las distintas necrópolis de una manera un tanto particular, caracterizada por la aglomeración de tumbas en determinados sectores separados por grandes espacios estériles, probablemente reflejo post mortem de unidades gentilicias o familiares - quizás etnicoidentitarias - (Muñoz et alii, 2009, 70).

En el terreno de la ritualidad también podemos observar algunos patrones muy similares, no sólo en Onoba y Ossonoba, sino en otras ciudades del Golfo de Cádiz, como Gades o Baelo Claudia, se trata de la ausencia generalizada de terra sigillata en los ajuares de las sepulturas, compuestos en su lugar por cerámica común, joyas (pendientes, anillos, collares, pulseras), amuletos, objetos de tocador y monedas.

Merece la pena destacar que de todos los ajuares recuperados en las necrópolis de Ossonoba y Ono$b a$, sólo se conoce una única pieza de terra sigilla$t a$ africana correspondiente a un plato del tipo C Hayes 45 , el cual servía de apoyo a la cabeza de un individuo en una sepultura de Horta do Ferragial. No obstante, como ya se ha comentado, ésta evidencia no debe ser tenida en cuenta, dado que sería registrada en un campo sepulcral relacionado con una villa privada. Asimismo, no debemos olvidar, que a pesar de que todas estas necrópolis contaron con una identidad común, no todas ellas generaron las mismas expresiones ante idénticos estímulos funerarios. Por ejemplo, aún cuando en ciudades como Carmo las monedas estuvieron ausentes de los ajuares, éstas aparecieron de manera testimonial en algunas sepulturas de Ossonoba, Onoba o Gades (Bendala, 2002, 142 y ss).

Las similitudes aquí presentadas no se registran únicamente en el medio urbano, sino que son apreciables en otros enclaves del litoral onubense donde pescadores y mercaderes de Onoba y Osonoba se cruzaban, es el caso por ejemplo de El Eucaliptal. En esta factoría se documenta un cuadro ritual muy semejante a los observados en las necrópolis analizadas en Portugal y España, con enterramientos infantiles en ánforas del tipo Almagro 51, o la presencia de un collar de oro idéntico al recuperado en la calle Alcaçarias (Campos et alii, e.p.).

Vemos, pues, que entre las vecinas ciudades de la Bética y del Sur de la Lusitania, las semejanzas entre sus necrópolis son mucho más numerosas que sus diferencias, las cuales como vimos pueden ser explicadas por los diferentes niveles de información y ritmos de investigación ocurridos en cada uno de estos núcleos urbanos. Estas semejanzas, presentes en otras ciudades del litoral gaditano, vendrían a confirmar la existencia de una gran ligazón económica y cultural entre el Sur de la Lusitania y la Bética, forjada fundamentalmente por su vinculación al mar. Ésta sería tan fuerte, que constituiría un factor de unión más que de separación, capaz de sobrepasar cualquier división administrativa impuesta entre ciudades pertenecientes a una misma área cultural, la antigua Turdetania.

\section{BibliografíA}

AA.VV. (1995), Tabula Imperii Romani (=TIR), Madrid, s.v. Ossonoba.

Amo y de La Hera, M. del (1976), "Restos materiales de la población romana de Onuba" Huelva Arqueológica, II, 86-97

Alarcão, J. de (1970), "Abraded and engraved late roman glass from Portugal”, Journal of Glass Studies, XII, 28-34.

Aguilar Camacho, G. (2004), "La necrópolis romana occidental de la Algodonera. Écija, Sevilla”, Anuario Arqueológico de Andalucía, 2001, III, 891-898.

Beltrán Fortés, J., (2000), "Mausoleos romanos de Torreparedones (Castro del Río/Baena, Córdoba): sobre la tumba de los Pompeyos y otro posible sepulcro monumental" Habis, 31, 113-136.

(2002), "La arquitectura funeraria en la Hispania meridional durante los siglos II a. C. I d. C.”, Espacios y usos funerarios en el Occidente Romano, II (Vaquerizo Gil, D., Ed.), Córdoba, 233-258.

Bendala Galán, M. (2002), "Perduraciones y romanización en Hispania a la luz de la arqueología funeraria: notas para una discusión”, Archivo Español de Arqueología, 75, 137-158. 
Bernardes, J. P. (2005), “As necrópoles de Ossonoba”, Caminhos do Algarve Romano, Catálogo de exposição do Museu Municipal de Faro, Faro, 26-34.

Campos, J. M., Vidal, N. y Ruiz, J. M. (2010), "Acerca de la condición jurídica de Onoba Aestuaria" Pyrenae, 41-1,50-75.

Campos, J. M., Fernández, L., O’Kelly, J., De Haro, J., y López, M. Á. (e. p.), "Nuevas aportaciones sobre la necrópolis de El Eucaliptal (Punta Umbría, Huelva). Economía, comercio y sociedad a través de sus manifestaciones funerarias”, Huelva Arqueológica, XIV.

Castilla, E., De Haro, J. y López, M. Á. (2001), Intervención arqueológica de urgencia en la calle Vázquez López no8 (Huelva). Informe Preliminar, Delegación Provincial de Cultura de la Junta de Andalucía en Huelva, Inédito.

(2004), "El solar n²5-27 de la Calle Vázquez López en la zona arqueológica de Huelva. La necrópolis sur de Onuba", Anuario Arqueológico de Andalucía, 2001, III, 503-511.

Cruz, M. (2009), Vita Vitri, O Vidro Antigo em Portugal, Lisboa.

De Haro, J., Castilla, E. y López, M. Á. (2006), "Intervención arqueológica en Plaza Ivonne Cazenave $\mathrm{n}^{\mathrm{O}} 1$ (Huelva). $4^{\mathrm{O}}$ y $5^{\mathrm{o}}$ fase de actuación”, Anuario Arqueológico de Andalucía, 2003, III, 577-587.

Donati, A. (1965), "Cippi e misure dei sepolcreti romani de Bologna”, Strenna Storica Bolognese, $X V, 89-97$.

Encarnação, J. d' (1984), Inscrições Romanas do Conventus Pacensis. Subsídios Para o Estudo da Romanização (=IRCP), Coimbra.

Fernández, L., Campos, J. M. y Vidal, N. (2013), "El mundo funerario en la ciudad romana de Onoba: las manifestaciones arquitectónicas de la necrópolis Norte”, Onoba, 1, 175-186.

Fernández, Á, Rodríguez, A. y García, M. (2001), Intervención arqueológica de urgencia. Excavación del solar C/San Andrés $n^{\circ} 5$ y Dr. Plácido Bañuelos $n^{\circ}$ 4-5. Memoria Científica. Delegación Provincial de Cultura de la Junta de Andalucía en Huelva, Inédito.

Frade, H. y Caetano, J. C. (1993), "Ritos Funerários Romanos no Nordeste Alentejano”, Actas do II Congresso Peninsular de História Antiga, Coimbra, 847-872.

Gamito, T. J., (1992), "Cemitério romano do século II/III - Faro, rua das Alcaçarias”, Conimbriga,
3, 99-118.

(1997), “A cidade de Ossonoba e o seu território envolvente”, Noventa séculos entre a Serra e o Mar (Barata, F. y Parreira, R., Coords.), Lisboa, 343-359.

Garrido, J. P. y Orta, E. Mª (1966), “Nuevo hallazgo de una tumba de incineración en los Cabezos de Huelva”, Ampurias, XXVIII, 209-215.

González, B. y Guerrero, O. (2008), Memoria científica de la intervención arqueológica de urgencia en el solar de Plaza San Pedro 4-5 de Huelva. Delegación Provincial de Cultura de la Junta de Andalucía en Huelva, Inédito.

González, D., Guerrero, O., Goyanes, S., y Lozano, C. (2001), Informe Preliminar: Actividad Arqueológica de Urgencia en las calles Vázquez López, Tres de Agosto, Plaza de las Monjas y Plaza Quintero Báez en la Zona Arqueológica de Huelva, en el marco del Proyecto de saneamiento de Huelva, cuenca del río Tinto, $2^{a}$ fase. Consejería de Cultura de la Junta de Andalucía en Huelva, Inédito.

Gómez, F., López, M. Á., Beltrán, J. M., Gómez, Á., y Campos, J. M. (2003), "Intervención arqueológica en el solar Plaza Ivonne Cazenave, 1 (Huelva)", Anuario Arqueológico de Andalucía, 2000, III, 577-587.

Jorge, A. M. (2002), L'Épiscopat de Lusitanie pendant l'Antiquité Tardive (IIIe - VIIe Siècles), Instituto Português de Arqueología, Lisboa.

Lorenzo y Leal, B. (1883), Onoba Listuaria (Huelva). Su historia, desde los más remotos tiempos hasta nuestros dias, Primera Parte, Huelva.

Márquez Pérez, J. (2006), Los Columbarios: arquitectura y paisaje funerario en Augusta Emerita, Ataecina, Colección de estudios históricos de la Lusitania, Mérida.

Mora Rodríguez, Mํ. C. (2005), Intervención arqueológica preventiva en c/Palacios, $n^{\circ} 9$. Memoria Preliminar, Delegación Provincial de Cultura de la Junta de Andalucía en Huelva, Inédito.

Muñoz, A., García, I., y Prados, F. (2009), "Espacios jerarquizados y áreas funerarias en la necrópolis oriental de Baelo Claudia (Tarifa, Cádiz). Nuevas perspectivas de estudio" Jorge Bonsor y la recuperación de Baelo Claudia (19171921), Catálogo de la Exposición celebrada en el Conjunto Arqueológico de Baelo Claudia en- 
tre el 4 de junio y el 30 de septiembre de 2009 , Sevilla, 59-77.

Osuna Ruiz, M. (1998), Informe de la actuación arqueológica en la C/ Palos, 15-17. Delegación Provincial de Cultura de la Junta de Andalucía en Huelva, Inédito.

Paula, R. M. y Paula, F. (1993), Faro, Evolução Urbana e Património, Faro.

Purcell, N. (1987), “Tomb and Suburb”, Römische Gräberstrassen. Selbstdarstellung-StatusStandard (Von Hesberg, H. y Zanker, P., Eds.), München, 25-41.

Rodrigues, S. (2004), As Vias Romanas do Algarve, Faro.

Rodríguez Neila, J. F. (1991), "Espacios de uso funerario con indicación de medidas en las necrópolis romanas", Conimbriga, XXX, 59-94.

Rosa, J. A. P., (1976), "Novas achegas para a localização de Ossonoba (Os últimos achados em Faro)", Anais do Municipio de Faro, 6, 37-42.

(1984), "Estamos em Ossonoba?", Anais do Município de Faro, 14, Faro.

Ruiz Osuna, A. B., (2005), "La via sepulchralis occidental: un ejemplo de monumentalización funeraria en Colonia Patricia”, Anales de Arqueología Cordobesa, 16, 79-104.

(2010), Colonia Patricia, centro difusor de modelos: topografia y monumentalizacion funerarias en Baetica, Monografias de Arqueologia Cordobesa, 17, Córdoba.

s/autor (1967), "Sepultura lusitanoromana em Faro”, O Arqueólogo Português, $3^{\mathrm{a}}$ série: 1, 119.

s/autor (1969), "Notícias dos Jornais”, O Arqueólogo Português, $3^{\mathrm{a}}$ série: $3,292$.

Sacchi, F. (2003), Ianua leti: l'architettura funeraria di Milano romana, Milano.

Sánchez Ramos, I., (2007), "La cristianización de las necrópolis de Cordvba. Fuentes escritas y testimonios arqueológicos”, Archivo Español de Arqueología, 80, 191-206.

(2010), Corduba durante la Antigüedad tardía. Las necrópolis urbanas, BAR International Series, 2126, Oxford.

Santos, M. L. E.V.A. (1971), Arqueologia Romana do Algarve, I, Lisboa.

Serra, M., Porfírio, E., Barbosa, R., Valinho, A., y Marques, J. N. (2006), "Balanço das Intervenções da Palimpsesto no Algarve: 2002 2005”, Actas do $3^{\mathrm{o}}$ Encontro de Arqueologia do Algarve, Xelb, 6/II, 207-212.

Teichner, F. (2008), Zwischen Land und Meer.
Entre tierra y mar. Studien zur Architektur und Wirt-schaftsweise ländlicher Siedlungen im Süden der römischen Provinz Lusitanien, Stvdia Lusitana, 3, Merida.

Teichner, F., Schierl, T., Gonçalves, A., y Tavares, P. (2006), "Sebastião Philippes Martins Estácio da Veiga e as necrópoles romanas de Ossonoba (Faro)", Actas do $3^{\mathrm{o}}$ Encontro de Arqueologia do Algarve, Xelb, 6/II, 161-170.

Vaquerizo Gil, D., (2002a), "Espacios y usos funerarios en Corduba”, Espacios y usos funerarios en el Occidente Romano, II (Vaquerizo Gil, D., Ed.), Córdoba, 141-200.

(2010), Necrópolis Urbanas en Baetica, Colección Documenta, 15, Secretariado de Publicaciones de la Universidad de Sevilla e Institut Català d’Arqueología Clásica (ICAC), Sevilla.

Vaquerizo, D. y Murillo, J. F. (2010), "Ciudad y suburbio en Corduba. Una visión diacrónica (siglos II a. C.-VII d. C.)", Las áreas suburbanas en la ciudad histórica. Topografía, usos, función (Vaquerizo Gil, D., Ed.), Monografías de Arqueología Cordobesa, 18, Córdoba, 455-522.

Viana, A., (1951), "O cemitério luso-romano do Bairro Letes”, Brotéria, 53, 145-165.

(1952), "Balsa y la necrópolis romana de as Pedras d'El Rei”, Archivo Español de Arqueologia, 25, 261-285

Vidal, N. y Campos, J. M. (2006), “Las necrópolis de Onuba”, Anales de Arqueología Cordobesa, 17/II, 13-34.

Viegas, C., (2011a), A ocupação romana do Algarve: estudo do povoamento e economia do Algarve central e oriental no período romano, UNIARQ, Série estudos e Memórias, 3, Lisboa.

(2011b), "Ritmos do povoamento e da economia do Algarve romano: entre o Mediterrâneo e o Atlântico", O Arqueólogo Português, 5/1, 15-204.

Zanker, P. (1992), Augusto y el poder de las imágenes, Madrid. 
